\title{
Article \\ Numerical Study of Constant Pressure Systems with Variable Speed Electric Pumps
}

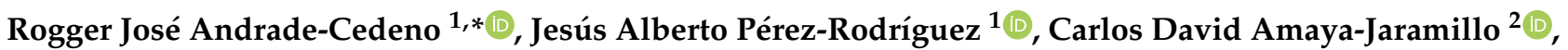 \\ Ciaddy Gina Rodríguez-Borges ${ }^{3}\left[\right.$, , Yolanda Eugenia Llosas-Albuerne ${ }^{1}\left(\mathbb{D}\right.$ and José David Barros-Enríquez ${ }^{4}(\mathbb{C}$
}

check for

updates

Citation: Andrade-Cedeno, R.J.;

Pérez-Rodríguez, J.A.;

Amaya-Jaramillo, C.D.;

Rodríguez-Borges, C.G.;

Llosas-Albuerne, Y.E.;

Barros-Enríquez, J.D. Numerical Study of Constant Pressure Systems with Variable Speed Electric Pumps. Energies 2022, 15, 1918. https:// doi.org/10.3390/en15051918

Academic Editors: Roberto Alonso González Lezcano,

Francesco Nocera and Rosa Giuseppina Caponetto

Received: 3 February 2022

Accepted: 3 March 2022

Published: 6 March 2022

Publisher's Note: MDPI stays neutral with regard to jurisdictional claims in published maps and institutional affiliations.

Copyright: (C) 2022 by the authors. Licensee MDPI, Basel, Switzerland. This article is an open access article distributed under the terms and conditions of the Creative Commons Attribution (CC BY) license (https:// creativecommons.org/licenses/by/ $4.0 /)$
1 Departamento de Electricidad, Facultad de Ciencias Matemáticas, Físicas y Químicas, Universidad Técnica de Manabí, Portoviejo 130150, Ecuador; jesus.perez@utm.edu.ec (J.A.P.-R.);

yolanda.llosas@utm.edu.ec (Y.E.L.-A.)

2 Departamento de Electricidad, Facultad de Ciencias de la Ingeniería, Universidad Técnica Estatal de Quevedo, Quevedo 120550, Ecuador; camaya@uteq.edu.ec

3 Departamento de Ingeniería Industrial, Facultad de Ciencias Matemáticas, Físicas y Químicas, Universidad Técnica de Manabí, Portoviejo 130150, Ecuador; ciaddy.rodriguez@utm.edu.ec

4 Departamento de Diseño, Facultad de Ciencias de la Industria y Producción, Universidad Técnica Estatal de Quevedo, Quevedo 120550, Ecuador; josedavid985@gmail.com

* Correspondence: rogger.andrade@gmail.com

\begin{abstract}
This work focuses on the modeling and simulation of constant pressure systems based on variable speed pumps, with the aim of studying and evaluating their performance from a multidisciplinary approach. Using the physical models of the Simscape library, from MATLAB/Simulink R2019b, two study cases are assembled consisting of: piping system, a hydropneumatic tank, centrifugal pumps with an induction motor, variable speed drives, and a control system. Case one is comprised of one pump at a fixed speed and another at variable speed, and case two with both pumps at variable speed. For the parameterization of the models, data from manufacturers and process requirements are used. The different stages of the control system are integrated and configured; these are constant V/f control, slip compensation, space vector modulation (SVM,) and pressure controller. The dynamic response of the system, power saving, transient current at startup, and harmonic distortion are evaluated. The results showed that both cases kept the pressure constant in the face of variable flow demand and smoothed out the current during startup. Case two saved more energy (between 28 and 49\%) but generated more harmonic distortion. In addition, both cases have better performance compared with traditional fixed-speed technologies.
\end{abstract}

Keywords: constant pressure system; pumping system; centrifugal pump; induction motor; variable speed drive; control system; energy efficiency; harmonic distortion; modeling and simulation

\section{Introduction}

At an industrial, commercial, and residential level, applications with pumps, compressors, fans, and others driven by electric motors represent $53 \%$ of total energy consumption, and there are new technologies that have the potential to reduce this electricity demand by between 20 to $30 \%$ [1]. In pumping applications with variable flow demand, the implementation of variable-frequency drives adapted to electric motors should be evaluated because of the potential energy savings that can be achieved and improvements in the overall performance of the system [2-5]. In these applications, the scalar control strategy with a constant $\mathrm{V} / \mathrm{f}$ ratio is the most feasible, mainly because of its simplicity and low-cost implementation [6-8]. There are several studies where scalar control with a constant V/f ratio was simulated for the speed control of an induction motor; for example, in an open loop with voltage and slip compensation to improve the performance in low frequencies [9], and adding a PID controller for automatic regulation in a closed loop to eliminate the speed position error $[8,10,11]$. The performances of the control system in the open and 
close loop were also compared, concluding that the close loop system presents a better performance [12-15]. For the particular case of centrifugal pumps driven by an induction motor with variable speed requirements, computer simulations have also been developed. For example, Lysenko and Simakov [16] simulated V/f scalar control in an open loop on an electric centrifugal pump, studying the dynamic response of the current, torque, speed, flow, and pressure in order to analyze and coordinate different modes of operation. An ideal source of DC voltage was used at the input of the inverter, even though the grid is normally AC. Furthermore, voltage waves and harmonic distortion were not studied. Abdelwanis and Selim [17] simulated the V/f control in a closed loop without a sensor (sensorless), that is, the axis speed was estimated from stator voltage and current, and the speed error correction was performed using a PID controller. They compared the harmonic distortion with and without the PID controller, finding improvements when operating with the PID controller. Gevorkov et al. [18] simulated a constant pressure pumping system by adding a feedback controller for automatic pressure regulation. They compared the P controller with the PI controller and showed that the second case performed better, reducing oscillation and position error. Arun Shankar et al. [19] conducted mixed simulation and real experimentation studies, where a cascade constant pressure system was implemented with pumps in parallel and a variable frequency drive. The algorithm implemented allowed the system to operate more efficiently, achieving energy savings between $15 \%$ and $45 \%$. No electrical analysis, such as current transient or harmonic distortion, was performed in this study. Oshurbekov et al. [20] compared two configurations: a single pump at variable speed and two pumps of lower power in parallel with one pump at a fixed speed and another at variable speed. The results showed that the second case was more efficient, with energy savings of $29.8 \%$. The analysis of electrical variables, such as current and voltage waveform, was not part of the scope of this study.

In this research, the modeling, simulation, and numerical study of two cases is carried out using MATLAB/Simulink R2019b, with the aim of developing a constant pressure system in a pumping station with variable flow demand, made up of two parallel centrifugal pumps driven by an induction motor. In case one, there is a fixed speed pump through a direct connection to the electrical grid and another variable speed pump. In case two, both pumps operate at variable speeds. Variable speed is achieved using a variable frequency drive governed by scalar control with a constant $\mathrm{V} / \mathrm{f}$ ratio and slip compensation, in conjunction with space vector modulation (SVM). The automatic pressure control is achieved with a PI controller. These two case studies are compared with the base case (both pumps at fixed speed), performing analysis of the dynamic response of the control system, evaluating the power consumption and savings, startup current transients, and harmonic distortion. This research is of scientific relevance because of its multidisciplinary approach methodology, with potential for application in industry, commerce, buildings, and agriculture, in addition to containing topics of interest in pumping system optimization, energy efficiency, and energy quality.

\section{Materials and Methods}

Figure 1 shows the methodology used and the aims of each stage. It begins with the study of the mathematical methods that govern the components of a pumping system in order to conceptualize models and systems. In the hydraulic and mechanical area: centrifugal pump theory, parallel pumping, affinity laws, piping systems, Darcy equation, Haaland equation, gas-charged accumulator. For the electrical and electronic part: the model of the induction motor in state space, the operability of the variable speed drive, the scalar control with constant $\mathrm{V} / \mathrm{f}$ ratio, the space vector modulation (SVM), the control system, and the PI controller. 
Study mathematical methods for pumping and piping systems (Centrifugal pump theory, affinity laws, Darcy equation, Haaland equation

Study mathematical methods for variable speed drives and control system. (Induction motor state space model, scalar control (V/f), space vector modulation (SVM), PI controller)

Review and select models in MATLAB/Simulink R2019b (Pump, accumulator, piping, motor, vsd, controller)

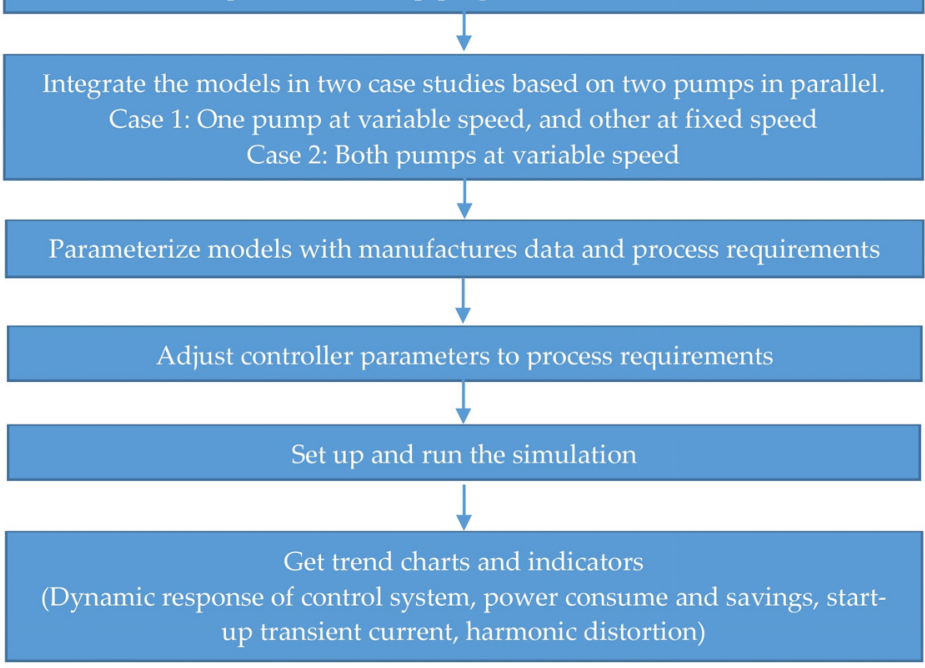

Conceptualize models and systems

Design case studies

$$
\begin{aligned}
& \text { Specify models and } \\
& \text { systems }
\end{aligned}
$$

Design the control system

Solve the equations behind the models

Comprehensive analyse hydraulic and electrical aspects, and carry out a comparative evaluation

Figure 1. Flow diagram of methodology.

Using the MATALAB/Simulink R2019b Simscape library, the blocks are reviewed, selected, and integrated to form two case studies, as described in Section 2.3. The models are parameterized using data from manufacturers and process requirements. Then all the stages of the control system are adjusted to meet the process requirements; these are: PI slip compensator, V/f scalar control, space vector modulation (SVM), and PI pressure controller. The simulation is run to solve the mathematical models, data and trend graphs are obtained for the subsequent analysis and evaluation. Finally, a comprehensive analysis of the hydraulic and electrical aspects of each case study is carried out, evaluating the dynamic response of the control system, power consumption and savings, starting transient current, and harmonic distortion. Based on these results, the case studies are compared to determine which one has the best performance. The novelty of this methodology lies in the use of Simscape physical models and the multidisciplinary analysis of the results. In other studies, linearized and approximate models are used, and the analysis is partial depending on the discipline (purely hydraulic or electric).

\subsection{Capacity Regulation Methods in Centrifugal Pumps}

Typical methods to regulate the capacity of a pumping system are on-off control, control valve, and speed variation. On-off control is justified for applications where there are tanks or reservoirs and where such precise control is not required. When demand flow adjustment is required, a control valve or variable speed drive should be used [21]. Flow regulation with a control valve can be seen in the laboratory work developed by [22], where a PID algorithm was implemented on a control valve placed in the discharge of a centrifugal pump operating at a fixed speed. The results showed a good performance of the flow control system, but the study did not delve into the performance of the centrifugal pump. However, fixed speed operation with a control valve can waste energy, while variable 
speed operation can increase energy efficiency [23]. When a centrifugal pump operates at a variable speed, it is important to monitor its efficiency curve to determine its performance based on the flow it delivers. This curve defines the efficiency "from the cable to the water", that is to say, the total efficiency, which considers the mechanical losses in the pump as well as the electrical losses in the motor and the variable speed drive [24]. Figure 2a shows the characteristic curves of a variable speed centrifugal pump, which is the preferred choice for operating in a region where the required flow remains controlled at best possible efficiency.

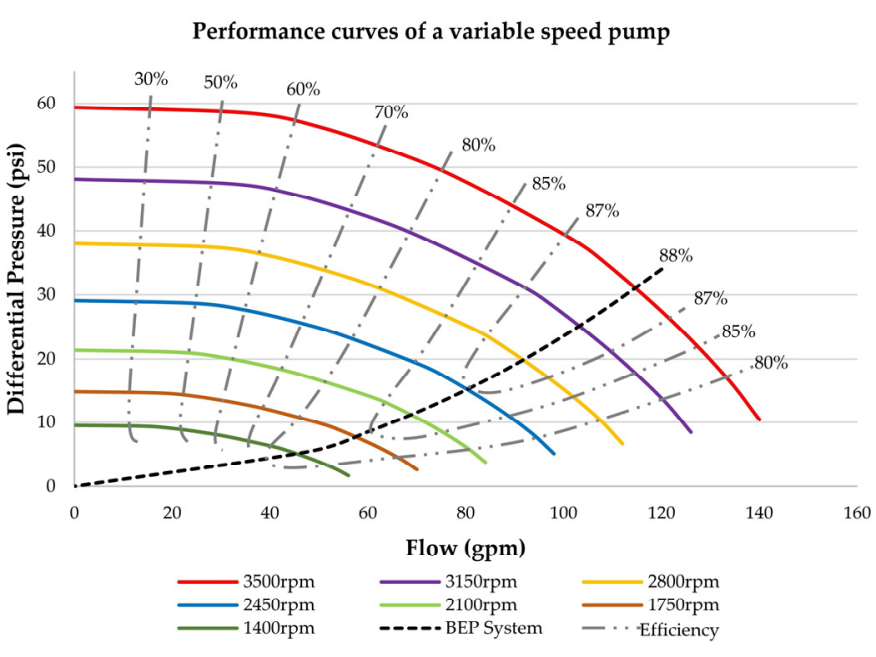

(a)

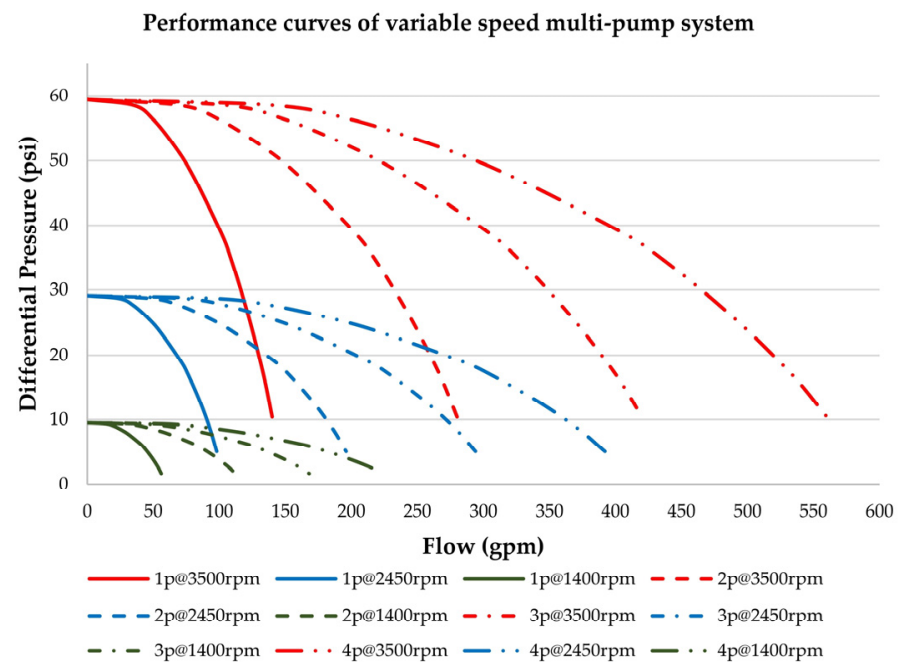

(b)

Figure 2. Performance curves in centrifugal pumps with speed variation: (a) in a single pump; (b) in a system of multiple pumps in parallel.

An alternative to using a single pump in an application with variable demand is to use several smaller capacity pumps connected in parallel since the multiple variations in the demand of the system prevent a single pump from operating constantly, close to the best efficiency point (BEP). Operating a centrifugal pump too far from the BEP to either the right or left of the curve can put equipment at risk from adverse effects such as cavitation, vibration, impeller damage, recirculation in suction, or unloading, and reduced life of seals and bearings $[21,24]$. These damages can be minimized by maintaining the operating flow in the Preferred Operating Region (POR). The POR is the range of flow rates on both sides of the BEP, where the operational reliability and hydraulic efficiency of the pump are not substantially degraded, so operating the pump within the POR generally results in lower energy consumption, higher reliability, and less impact on the useful life of the equipment. Most centrifugal pumps have a POR between 70-120\% of the BEP [25].

Figure $2 \mathrm{~b}$ shows the performance curves of a multipump system at variable speeds for different speeds. Variation in speed allows greater flexibility in operation and provides better performance for the system. In the study developed by Ahmed et al. [26], two configurations of multiple pump systems are presented: the first with a single pump at a variable speed, and the second where all the pumps operate at variable speed. The diagrams of both configurations can be seen in Figure 3. 


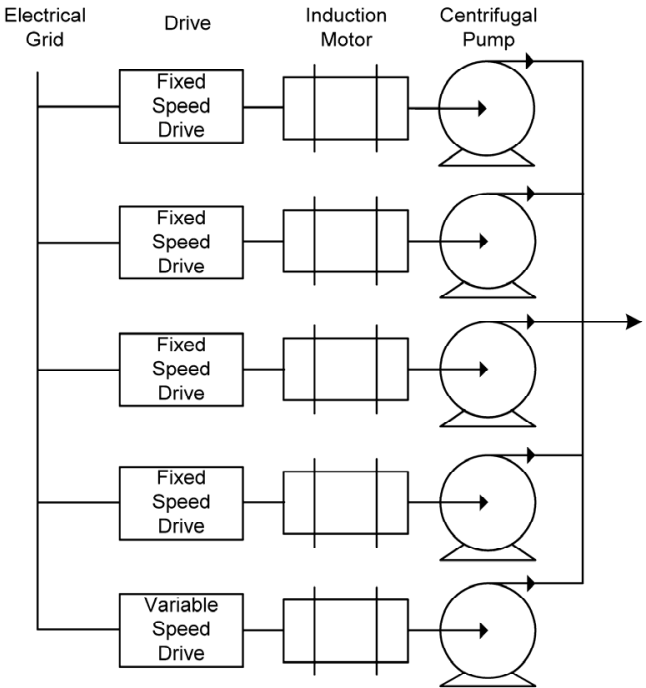

(a)

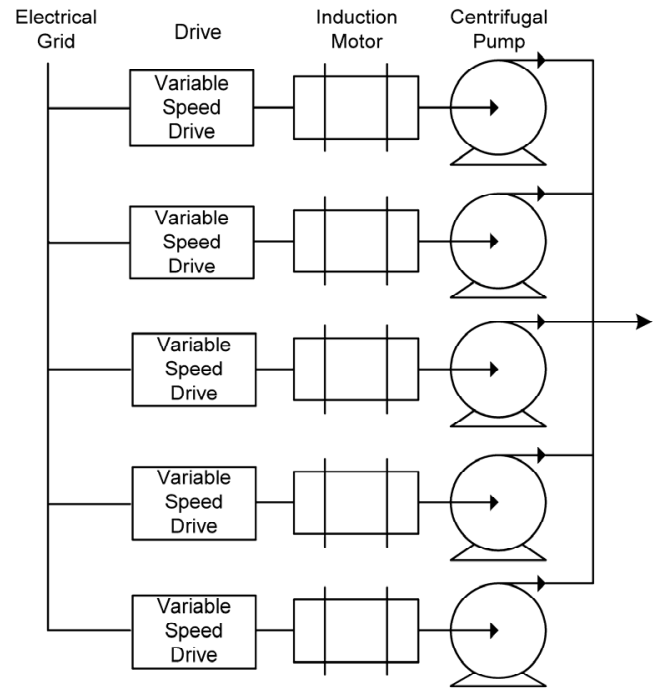

(b)

Figure 3. System of multiple pumps in parallel: (a) with a single pump at variable speed; (b) with all pumps at variable speed.

\subsection{Electrical Power and Control System}

There are different types of motors to drive pumps, but the induction motor is one of the most widely used because of the advantages it presents compared with other electric machines $[11,14,27,28]$. The accelerated advance of microprocessor systems and power electronics has made it possible to position variable speed drives as the main technology for motion control in applications driven by induction motors [10,29]. These types of equipment reduce the input energy to the motor when it is not operating at full load, which allows energy savings and operational improvements in systems that previously used motors without any type of speed control.

As concerns control techniques, there are two broad categories used by variable speed drives: scalar control and vector control. The most widely used scalar control technique is voltage-frequency $(\mathrm{V} / \mathrm{f})$ control, and vector control includes oriented field control and direct torque control [28-30]. Scalar control is less precise and presents a limited response in torque compared with other control techniques; it is simple to implement, it presents lower losses in switching, reduced computational processing, and a lower cost of implementation $[4,11,12,14,30]$. Some of the most common applications driven by the variable speed drive induction motor are pumps, compressors, fans, and small machines that operate at high speeds, but also, these types of applications require a strategy of simple control and moderate precision, so the $\mathrm{V} / \mathrm{f}$ control is the most feasible in these cases [6-8].

Automatic process controllers can also help improve the performance of electromechanical systems. The implementation of better monitoring, control, and optimization strategies improves the energy performance directly through the reduction of waste (very frequently associated with undue oscillations in the process) and indirectly through better maintenance practices [31]. The most widely used automatic process controller is the PID controller, present in more than $95 \%$ of control loops, constituting an important tool for improving productivity, quality, and energy efficiency [32]. Research conducted by Gomes et al. [33] on energy efficiency in industrial processes and PID controllers demonstrates how an adequate control strategy together with a correct controller adjustment procedure can contribute to saving energy consumption.

\subsection{Study Cases for Modeling and Simulation}

Figure 4 shows the two cases to be modeled, simulated, and studied, which are made up of two pumps connected in parallel supplying flow and pressure to a water network (system) where there is a variable demand for flow and constant pressure needs to be 
maintained. When there are low flow rates, both cases operate with a single pump at variable speed. However, it is necessary to operate the two pumps in parallel if the flow increases; in this scenario, case one operates with one pump at a fixed speed and the other at a variable speed, and case two operates with both pumps at variable speed. In the discharge head of each pumping group, there is an ideal pressure sensor (simulating a manometer or pressure transducer) and an ideal flow sensor (simulating a flow meter). The models of the hydraulic, mechanical, electrical, and control components were obtained from Simulink's Simscape library in the R2019b version of MATLAB. These models are detailed below.

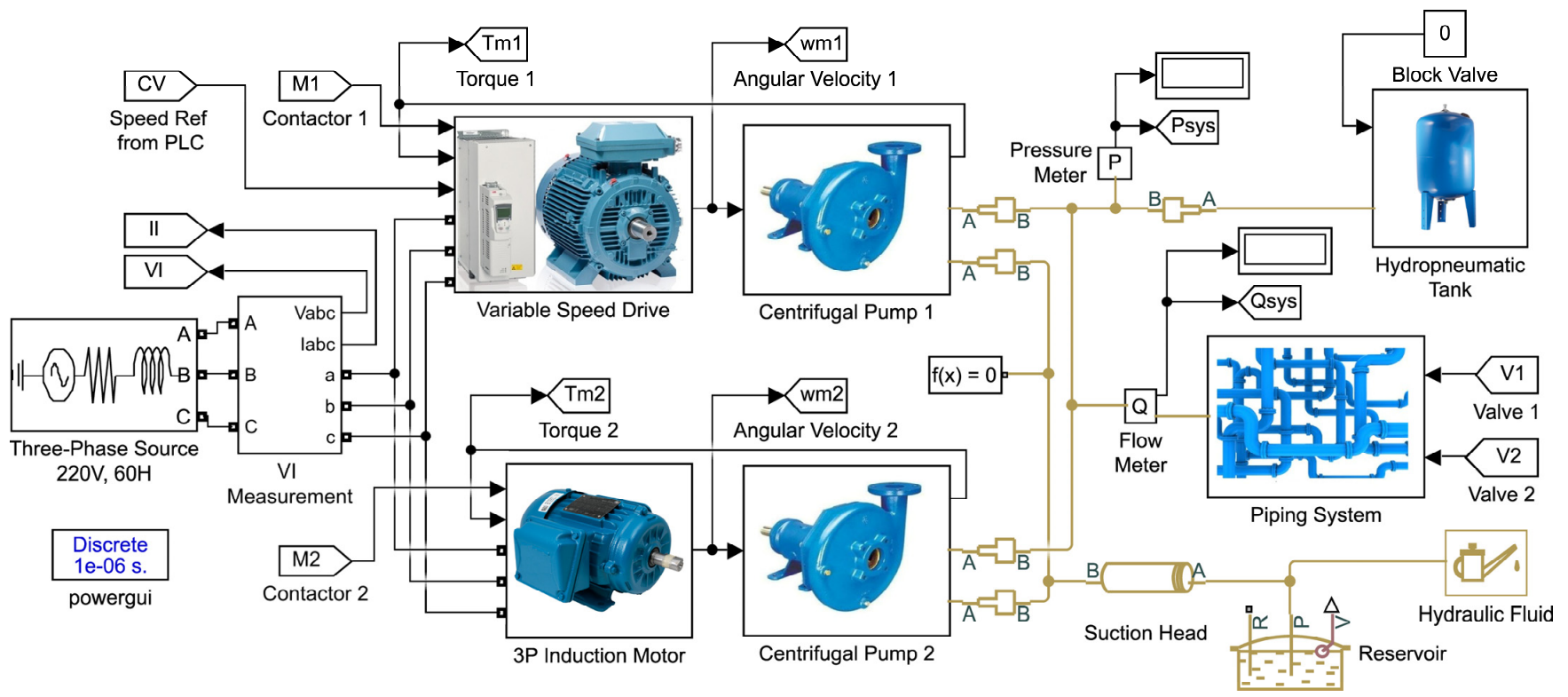

(a)

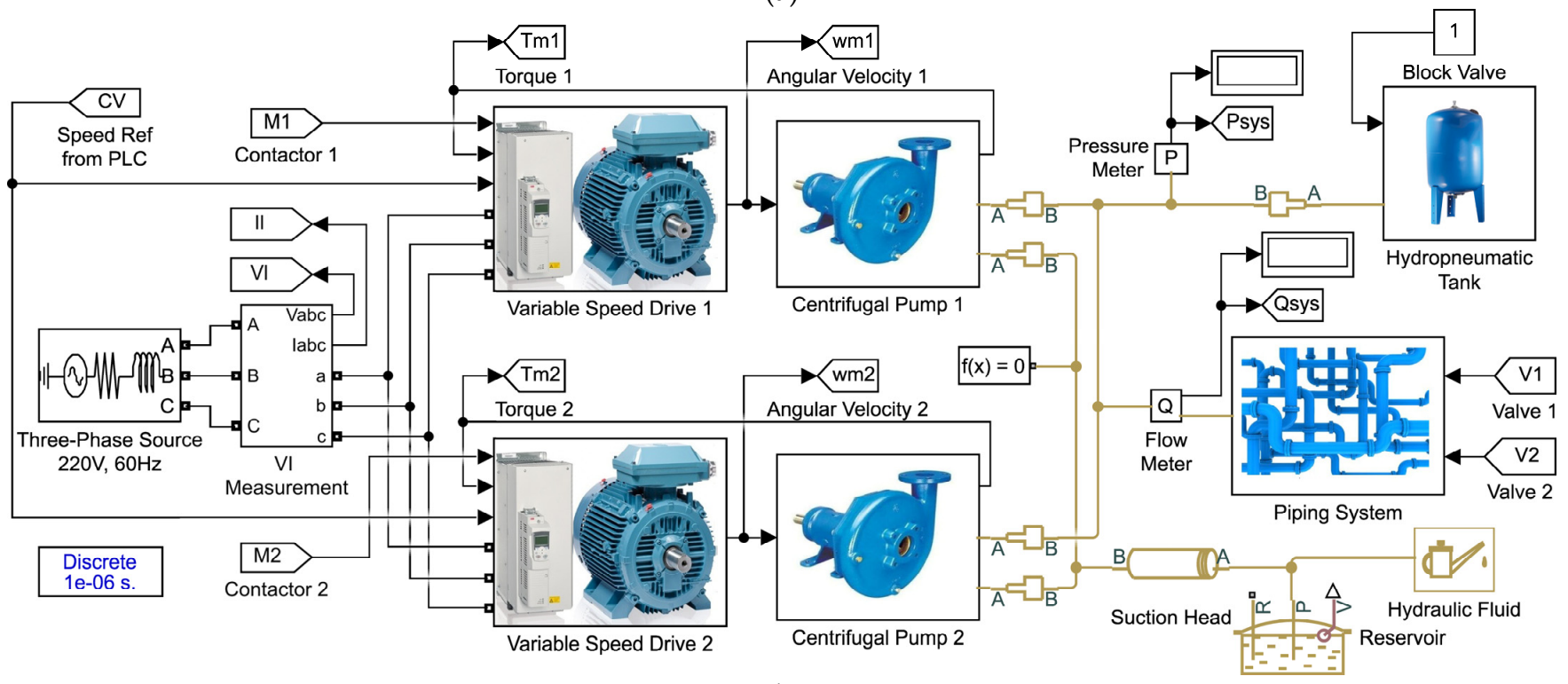

(b)

Figure 4. Case studies modeled in Simulink: (a) Case one: only one pump at variable speed. (b) Case two: both pumps at variable speed.

\subsubsection{Pumping System Model}

Figure 5 shows the pumping system model, where the centrifugal pump is the main component. The pump has a mechanical and hydraulic component. 


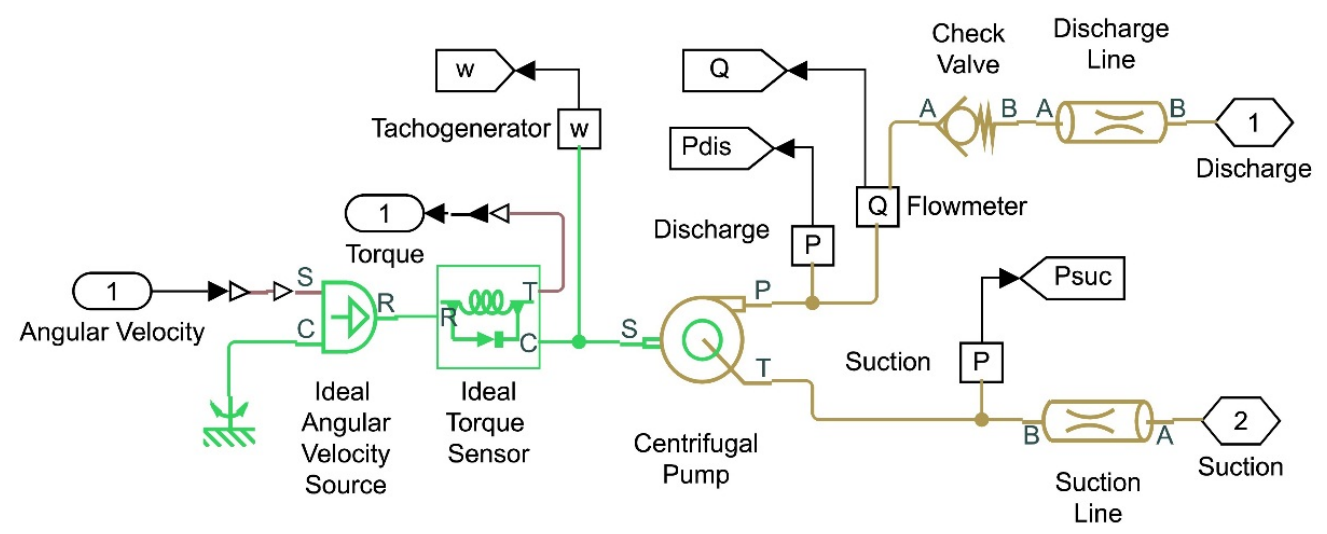

Figure 5. Pump train model developed in Simulink.

The mechanical component corresponds to an ideal source of angular velocity (from the induction motor) and an ideal torque load (towards the induction motor). The hydraulic component comprises a suction pipe and a discharge pipe. In addition, a check valve is installed in the discharge to isolate the pump when it goes out of operation. An ideal pressure sensor is connected to both sides, simulating a manometer or pressure transducer, and an ideal flow sensor is also used at the discharge, simulating a flow meter. The centrifugal pump is parameterized with the performance curve obtained from the datasheet provided by the manufacturer.

The characterization of the centrifugal pump is carried out using two one-dimensional search tables: (i) differential pressure vs. flow and (ii) brake power vs. flow-both at nominal angular velocity and flow density. To obtain the parameters at another angular velocity, the laws of affinity are used [34]. Equations (1)-(9) describe the complete model.

$$
\begin{gathered}
q_{\text {nom }}=q \frac{\omega_{\text {nom }}}{\omega} \\
p=p_{\text {nom }}\left(\frac{\omega}{\omega_{\text {nom }}}\right)^{2} \frac{\rho}{\rho_{\text {nom }}} \\
P_{\text {hyd_nom }}=p_{\text {nom }} q_{\text {nom }} \\
P_{\text {hyd }}=P_{\text {hyd_nom }}\left(\frac{\omega}{\omega_{\text {nom }}}\right)^{3} \frac{\rho}{\rho_{\text {nom }}} \\
P_{\text {hyd } 0}=p_{E} q_{\text {nom }}\left(\frac{\omega}{\omega_{\text {nom }}}\right)^{3} \\
P_{\text {fr }}=\left(T_{0}+k_{p} p\right) \omega \\
P_{\text {mec }}=P_{\text {hyd } 0}+P_{f r} \\
T=\frac{P_{\text {mec }}}{\omega} \\
\eta=\frac{P_{\text {hyd }}}{P_{\text {mec }}}
\end{gathered}
$$

\subsubsection{Hydropneumatic Tank Model}

Figure 6 shows the model of the hydropneumatic tank, consisting of an accumulator tank with precharged gas, a connection pipe between the tank and the water network, and a blocking valve. The accumulator tank comprises a chamber with precharged gas and a chamber with fluid, which is connected to a hydraulic system. The process is mathematically modeled with Equations (10)-(15) [35]. 


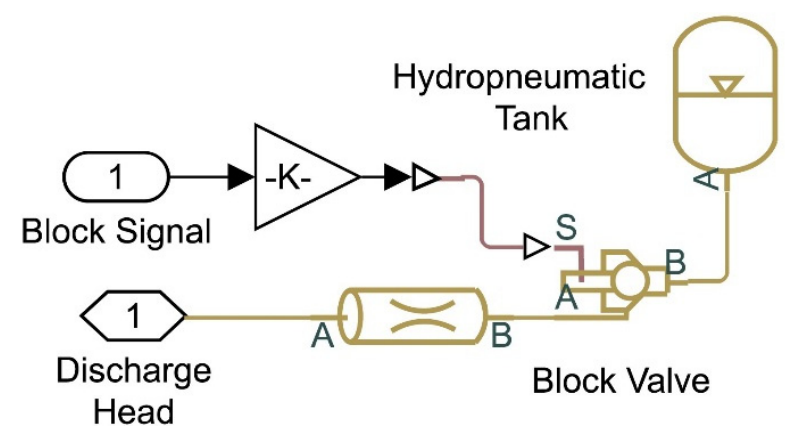

Figure 6. Hydropneumatic tank model developed in Simulink.

$$
\begin{gathered}
\left(p_{G}+p_{A}\right)\left(V_{T}-V_{F}\right)^{k}=\left(p_{p r}+p_{A}\right) V_{T}^{k} \\
p_{F}=p_{G}+p_{T D} \\
p_{T D}=\left\{\begin{array}{cc}
K_{S}\left(V_{F}-V_{C}\right)+K_{d} q_{F}^{+}\left(V_{F}-V_{C}\right) & \text { if } V_{F} \geq V_{C} \\
K_{S} V_{F}-K_{d} q_{F}^{-} V_{F} & \text { if } V_{F} \leq 0 \\
0 & \text { opposite case }
\end{array}\right\} \\
q_{F}^{+}=\left\{\begin{array}{cc}
q_{F} & \text { if } q_{F} \geq 0 \\
0 & \text { opposite case }
\end{array}\right\} \\
q_{F}^{-}=\left\{\begin{array}{cc}
q_{F} & \text { if } q_{F} \leq 0 \\
0 & \text { opposite case }
\end{array}\right\} \\
q_{F}=\frac{d V_{F}}{d t}
\end{gathered}
$$

At $t=0$, the initial condition is $V_{F}=V_{i}$, where $V_{i}$ is a parameter that can be entered initially.

\subsubsection{Piping System Model}

The water network, or piping system, is shown in Figure 7.

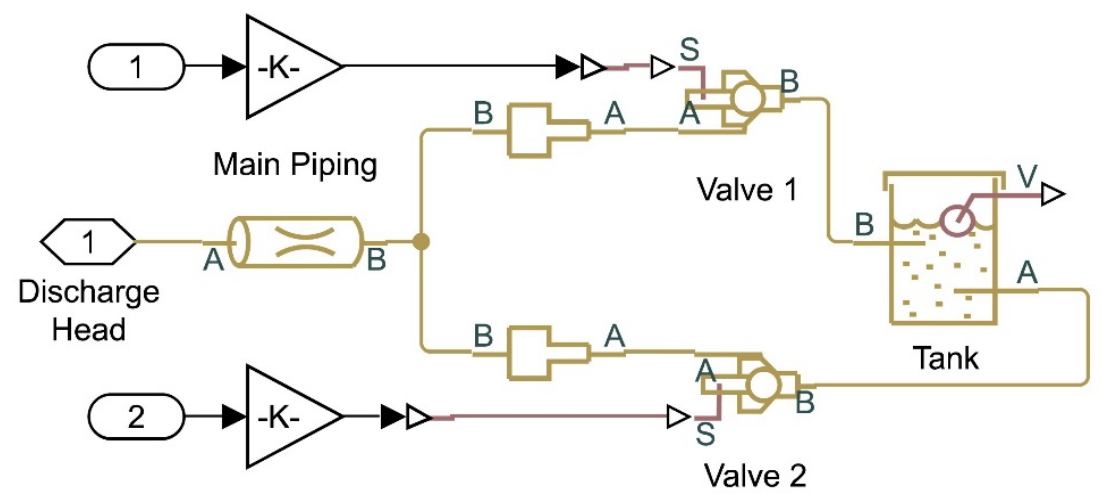

Figure 7. Model of the piping system developed in Simulink.

In this model, there is the main pipeline, consumption valves that simulate the variable flow demand, and a discharge tank. The pipe is modeled with a circular cross section, taking into consideration only the resistive property of the pipe. The Darcy equation is used to calculate the pressure loss due to the friction, and the Haaland approximation is used to calculate the friction factor in the turbulent regime. In the transition of regimens, 
from laminar to turbulent, the friction factor is determined by linear interpolation. As a result, the section of pipe is modeled according to Equations (16)-(18) [36].

$$
\begin{aligned}
& p=f \frac{\left(L+L_{e q}\right)}{D_{H}} \frac{\rho}{2 A^{2}} q \cdot|q| \\
& f=\left\{\begin{array}{lr}
K_{s} / R_{e} & \text { if } \operatorname{Re} \leq R e_{L} \\
f_{L}+\frac{f_{T}-f_{L}}{\operatorname{Re}_{T}-\operatorname{Re}_{L}}\left(\operatorname{Re}-\operatorname{Re}_{L}\right) & \text { if } R e_{L} \leq \operatorname{Re}<\operatorname{Re}_{T} \\
\frac{1}{\left(-1.8 \log _{10}\left(\frac{6.9}{\operatorname{Re}}+\left(\frac{r / D_{H}}{3.7}\right)^{1.11}\right)\right)^{2}} & \text { if } \operatorname{Re} \geq \operatorname{Re} e_{T}
\end{array}\right\} \\
& R e=\frac{q \cdot D_{H}}{A \cdot v}
\end{aligned}
$$

\subsubsection{Induction Motor Model}

To simulate the induction motor, the asynchronous machine model is used. This block makes it possible to model three-phase induction motors of the winding rotor, squirrel cage,

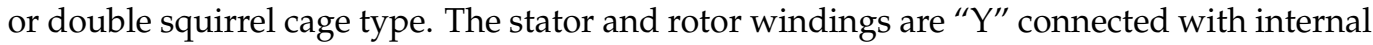
neutral. The electrical component of the machine is represented by a six-order state-space model (for double squirrel cage machine) or a fourth-order state-space model (for single squirrel cage machine), and the mechanical part is modeled by a second-order system [37]. In Figure 8, the equivalent circuit of the electrical system of the asynchronous double cage machine is shown under the reference frame $d q$. The electrical system is governed by Equations (19)-(34).
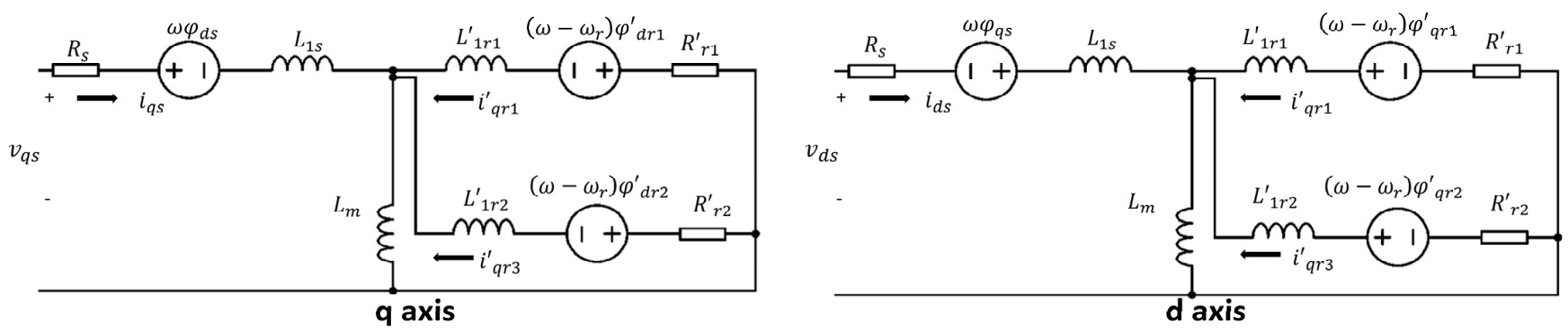

Figure 8. Equivalent circuit for double cage induction machine.

$$
\begin{gathered}
V_{q s}=R_{s} i_{q s}+d \varphi_{q s} / d t+\omega \varphi_{d s} \\
V_{d s}=R_{s} i_{d s}+d \varphi_{d s} / d t-\omega \varphi_{q s} \\
0=R_{r 1}^{\prime} i_{q r}^{\prime}+d \varphi_{q r 1}^{\prime} / d t+\left(\omega-\omega_{r}\right) \varphi_{d r 1}^{\prime} \\
0=R_{r 1}^{\prime} i_{d r 1}^{\prime}+d \varphi_{d r}^{\prime} / d t-\left(\omega-\omega_{r}\right) \varphi_{q r 1}^{\prime} \\
0=R_{r 2}^{\prime} i_{q r 2}^{\prime}+d \varphi_{q r 2}^{\prime} / d t+\left(\omega-\omega_{r}\right) \varphi_{d r 2}^{\prime} \\
0=R_{r 2}^{\prime} i_{d r 2}^{\prime}+d \varphi_{d r 2}^{\prime} / d t-\left(\omega-\omega_{r}\right) \varphi_{q r 2}^{\prime} \\
T_{e}=1.5 p\left(\varphi_{d s} i_{q s}-\varphi_{q s} i_{d s}\right) \\
\varphi_{q s}=L_{s} i_{q s}+L_{m} i_{q r}^{\prime} \\
\varphi_{d s}=L_{s} i_{d s}+L_{m} i_{d r}^{\prime} \\
\varphi_{q r 1}^{\prime}=L_{r 1}^{\prime} i_{q r 1}^{\prime}+L_{m} i_{q s} \\
\varphi_{d r 1}^{\prime}=L_{r 1}^{\prime} i_{d r 1}^{\prime}+L_{m} i_{d s} \\
\varphi_{q r 2}^{\prime}=L_{r 2}^{\prime} i_{q r 2}^{\prime}+L_{m} i_{q s}
\end{gathered}
$$




$$
\begin{gathered}
\varphi_{d r 2}^{\prime}=L_{r 2}^{\prime} i_{d r 2}^{\prime}+L_{m} i_{d s} \\
L_{s}=L_{l s}+L_{m} \\
L_{r 1}^{\prime}=L_{l r 1}^{\prime}+L_{m} \\
L_{r 2}^{\prime}=L_{l r 2}^{\prime}+L_{m}
\end{gathered}
$$

Equations (35) and (36) apply to the mechanical component.

$$
\begin{gathered}
\frac{d}{d t} \omega_{m}=\frac{1}{2 H}\left(T_{e}-F \omega_{m}-T_{m}\right) \\
\frac{d}{d t} \theta_{m}=w_{m}
\end{gathered}
$$

The induction motor is used in two connections: with a direct connection to the grid (frequency and nominal speed) and with a connection to a variable speed drive (frequency and variable speed). Figure 9a shows the model of the induction motor with a direct connection to the grid, and in Figure $9 \mathrm{~b}$ is the model for a variable speed drive made up of an induction motor and a frequency inverter.

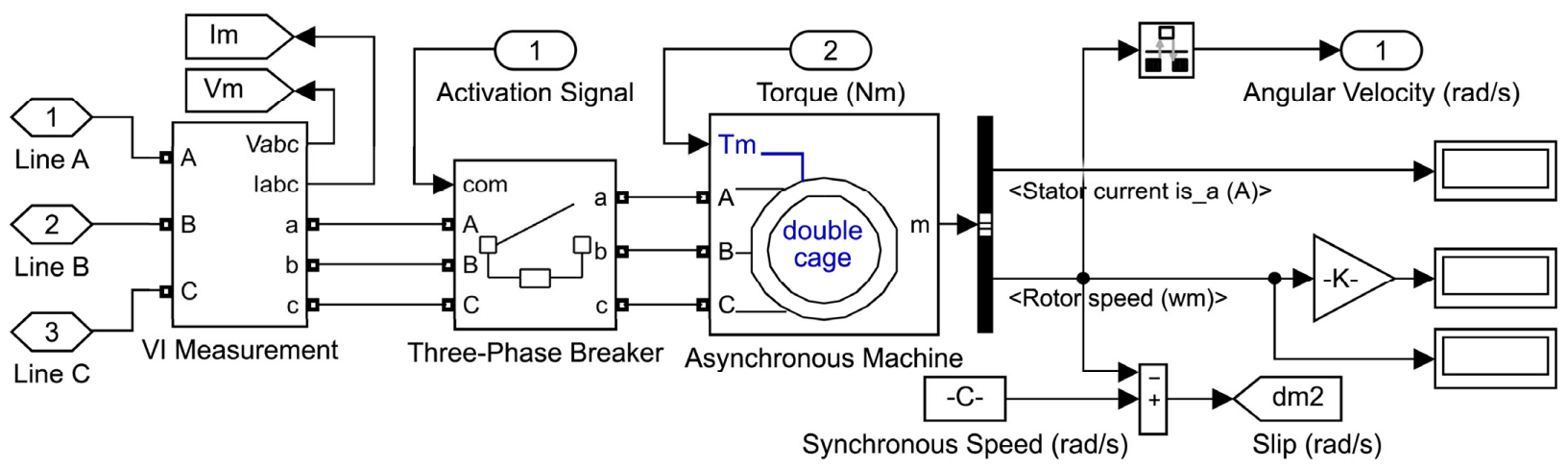

(a)

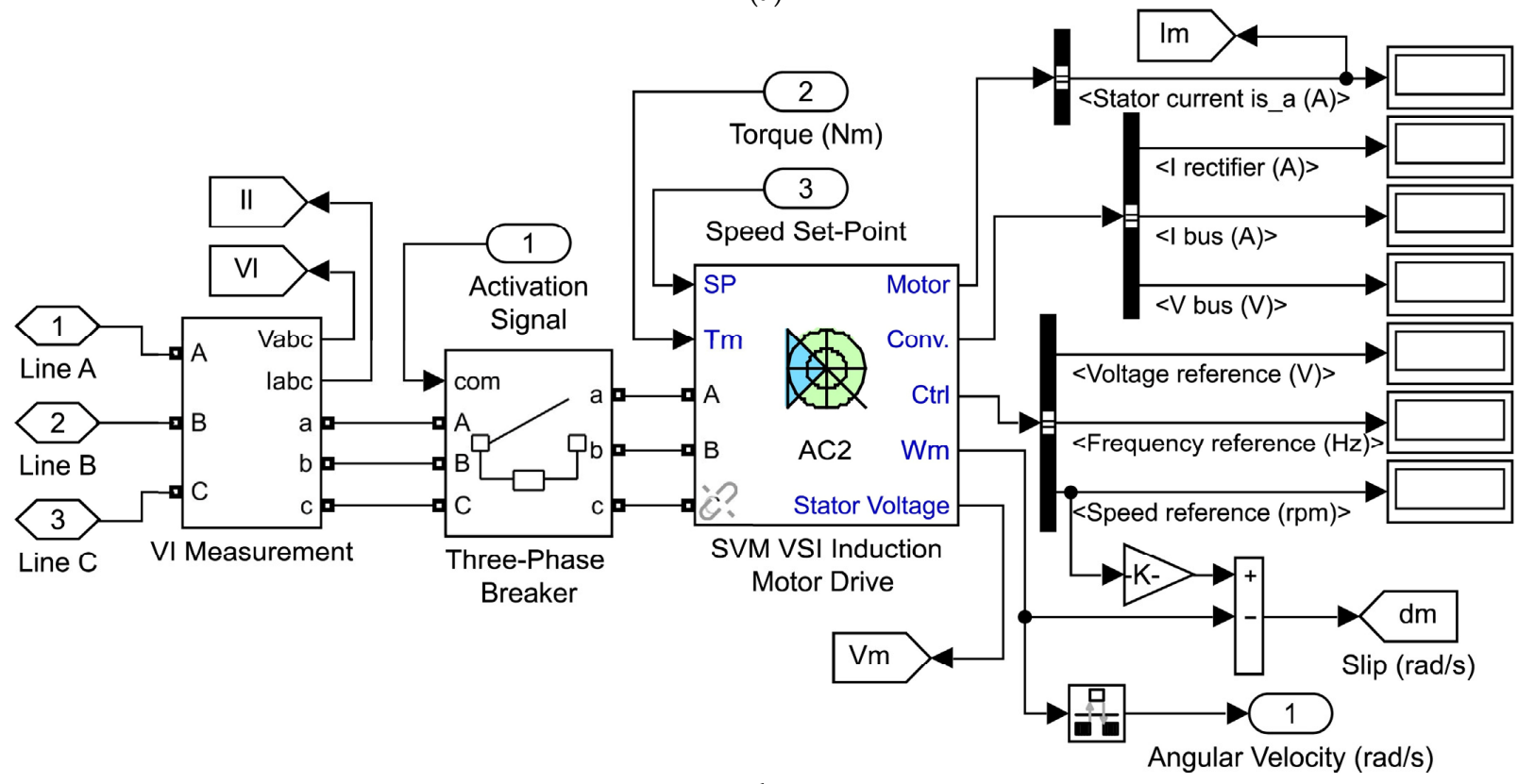

(b)

Figure 9. Simulink models of the three-phase induction motor with its drives and meters: (a) with a direct connection to the grid at nominal speed; (b) with variable speed drive. 


\subsubsection{Variable Speed Drive Model}

The variable speed drive is modeled with the block Drive AC2 "Space Vector PWM VSI Induction Motor Drive", which contains an asynchronous and a PWM-VSI variable frequency drive. The asynchronous machine is configured as a three-phase induction motor, and its variable frequency converter is made up of a three-phase rectifier, DC link, three-phase inverter, and control system, as seen in Figure 10a. Both the inverter and the rectifier of the block $\mathrm{AC} 2$ are based on the Universal Bridge, which allows the modeling and simulation of static converters using forcibly switched devices (GTO, IGBT, MOSFET) and naturally switched power electronic devices (diodes or thyristors) connected in a bridge configuration [38]. In this work, a rectifier made up of power diodes and an inverter based on IGBTs were selected.

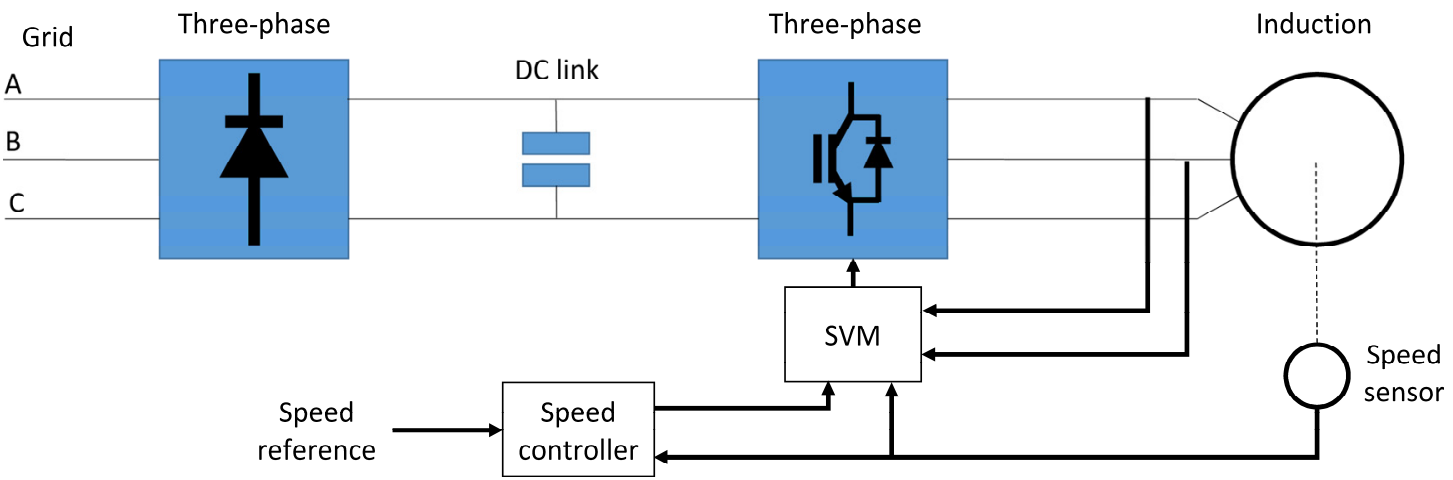

(a)

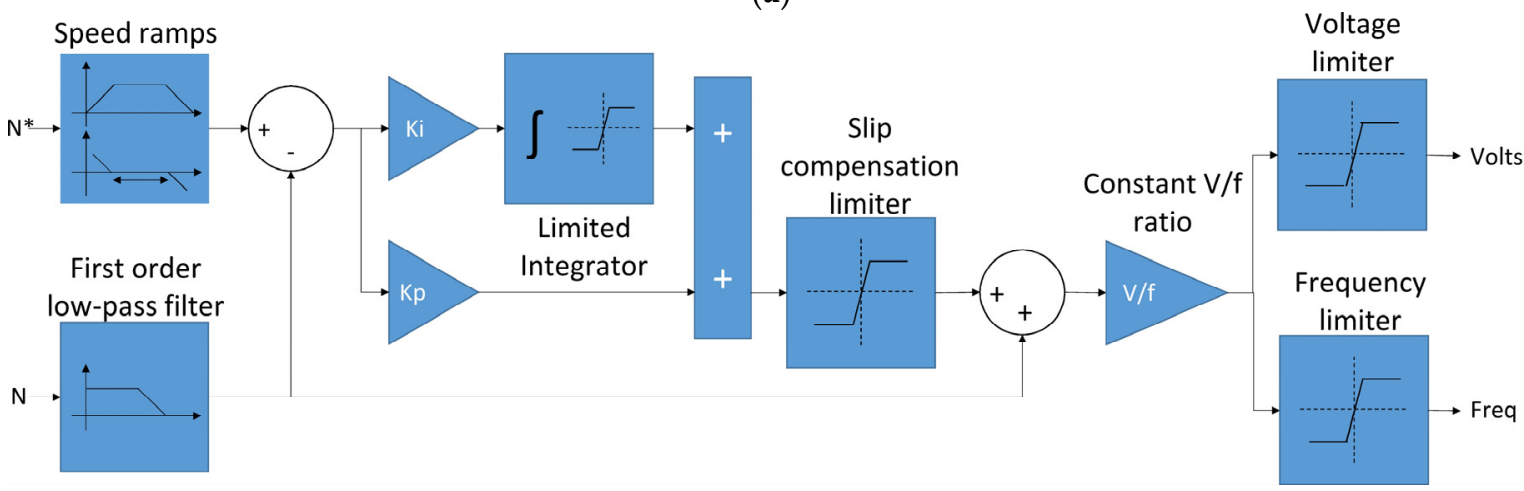

(b)

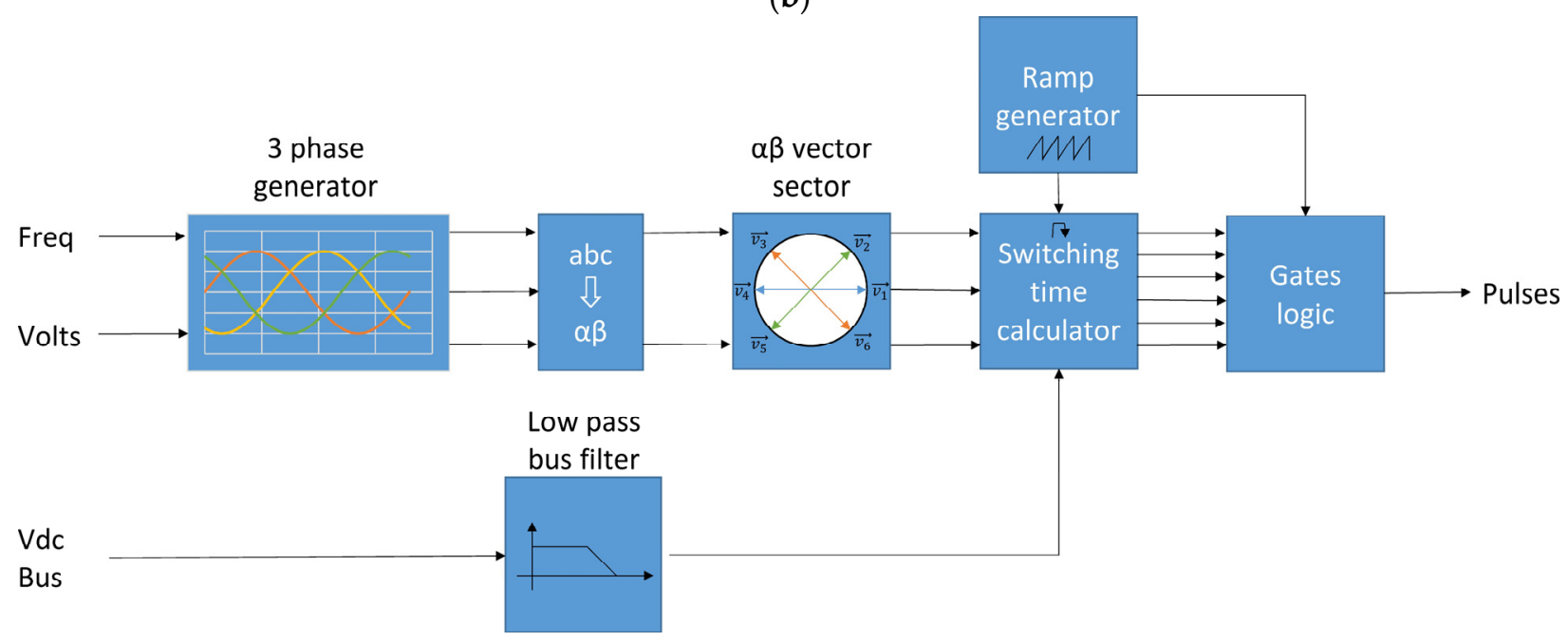

(c)

Figure 10. Block diagram of the Drive AC2 model in Simulink: (a) general power and control system diagram; (b) speed controller; (c) space vector modulation (SVM). 
Regarding the speed controller, the Drive AC2 has a closed loop speed control, made up of the classic V/f scalar control plus a slip compensator. Figure $10 \mathrm{~b}$ shows the block diagram of the speed controller, which is fed back with a tachogenerator connected to the motor shaft. The slip compensator, based on a PI controller, corrects the speed error in the motor. The constant $\mathrm{V} / \mathrm{f}$ ratio block allows the fundamental component of the voltage to the motor to have the desired amplitude and frequency. This is why it provides the voltage and frequency reference to the PWM generator [39]. Figure 10c shows the block diagram of the PWM generator based on space vector modulation (SVM), whose mission is to generate the control pulses for the IGBTs [39].

\subsubsection{Process Control System}

Figure 11 shows the block diagram of the pumping process control system. It has a PI pressure controller as an external loop and a slip compensator as an internal loop. Feedback for each control loop is achieved with a pressure transmitter and a tachometer, respectively. In practice, variable speed drives contain a PLC that provides digital inputs and outputs to connect discrete signals, analog inputs to receive sensor signals, analog outputs to control actuators, blocks to program PID algorithms, and specialized macros for pump control.

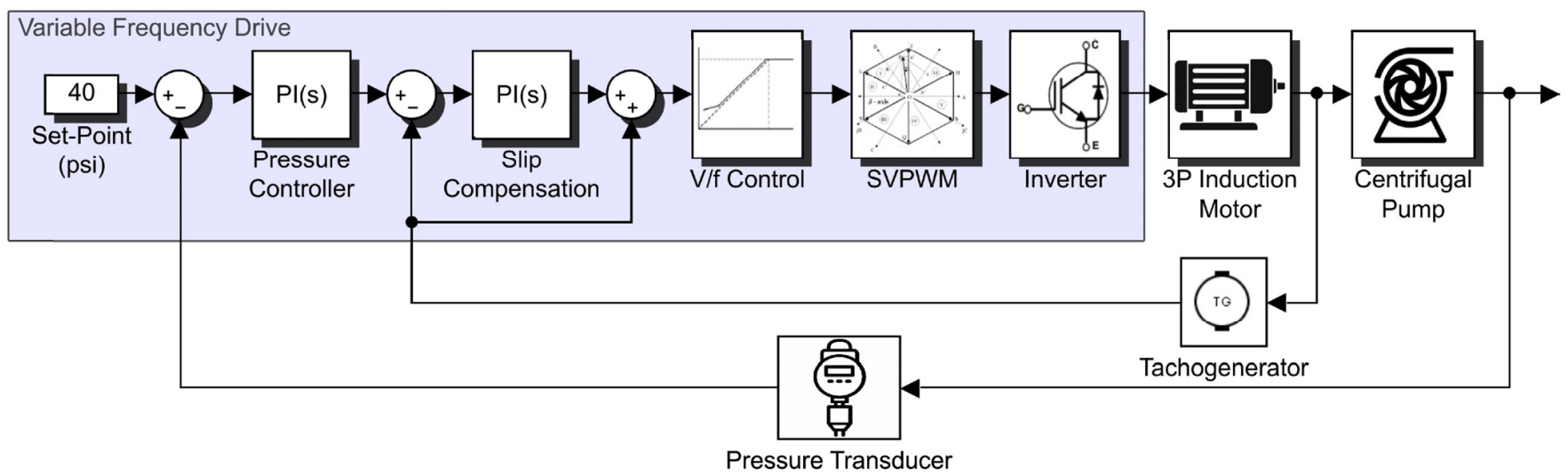

Figure 11. Block diagram of the pumping process control system.

The mathematical representation of the PID control algorithm is presented in Equations (37) and (38).

$$
\begin{gathered}
u(t)=K_{p}\left(e(t)+\frac{1}{T_{i}} \int_{0}^{t} e(t) d(t)+T_{d} \frac{d e(t)}{d t}\right) \\
K_{i}=\frac{K_{c}}{T_{i}} \quad K_{d}=K_{c} \cdot T_{d}
\end{gathered}
$$

The controller parameters $K_{p}, T_{i}$, and $T_{d}$, can be determined by applying various analytical or experimental techniques [40].

\section{Results and Discussion}

For the simulations, 120 gpm @ $35 \mathrm{~m}$ and 3500 rpm was considered, with a three-phase induction motor of $5 \mathrm{HP}, 220 \mathrm{Vac}, 60 \mathrm{~Hz}$, and two poles. The study cases were contrasted with each other and with the base case. The base case consisted of operating the pumps at a fixed speed through a direct connection to the electrical grid, requiring a hydropneumatic tank and an on-off control with hysteresis. For the base case, a hydropneumatic tank of 80 gal was considered. To reduce the on/off frequency of the pump, the capacity of the hydropneumatic tank must be increased, or the hysteresis band must be widened, which can make the application more expensive and affect the quality of the service because of low pressures. When upgrading the traditional on-off control for a regulatory control with variable speed drive, certain advantages and disadvantages were observed, which are detailed below. 


\subsection{Dynamic Response}

Two tests were carried out to study the dynamic response:

- Test 1: In low flow conditions with a pump operating at variable speed. This operation was the same in both study cases;

- Test 2: In high flow conditions with two pumps operating in parallel. In case one, one pump operated at a fixed speed and the other at variable speed, and in case two, both pumps were at variable speed.

In both tests, the pressure set point was set at $40 \mathrm{psi}$, and the acceleration/deceleration ramps of the variable speed drive were set at $3600 \mathrm{rpm} / \mathrm{s}$. The hydropneumatic tank capacity was reduced to 10 gal, which is an $87.5 \%$ reduction from the base case. The system responses were for step-type disturbances produced by sudden changes in the consumption valve. These disturbances were ideal and sufficiently drastic since, in a real system, every valve has a response time, even those of the quick opening type.

The results of test 1 are presented in Figure 12, where the dynamic response of the pressure, flow, and slip is shown, under three scenarios: with slip compensation and a hydropneumatic tank (Figure 12a), no-slip compensation (Figure 12b), and without the hydropneumatic tank (Figure 12c). As can be seen, in the three scenarios, it was possible to keep the pressure constant at $40 \mathrm{psi}$ in view of the variable flow demand. When it was operated with a hydropneumatic tank (Figures $11 \mathrm{~b}$ and 12a), the pressure overshoot did not exceed $10 \%$ of the set point; when the tank was removed (Figure 12c), the overshoot exceeded $50 \%$. This shows that it is not advisable to completely eliminate this element since it contributes to the damping of pressure transients due to sudden changes in demand and prevention of water hammer [41], in addition to improving the energy efficiency of the system when operating at low flow rates [42]. The action of the slip compensator is also observed. In Figure 12a, slip compensation is active, while in Figure 12b, it is inactive. As observed, a slight improvement in the transient response is achieved (Figure 12a), but this improvement was not representative.
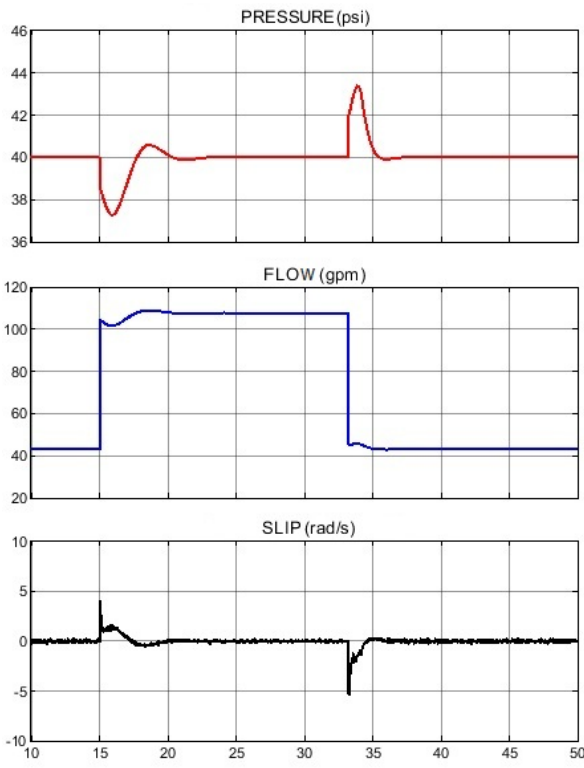

(a)
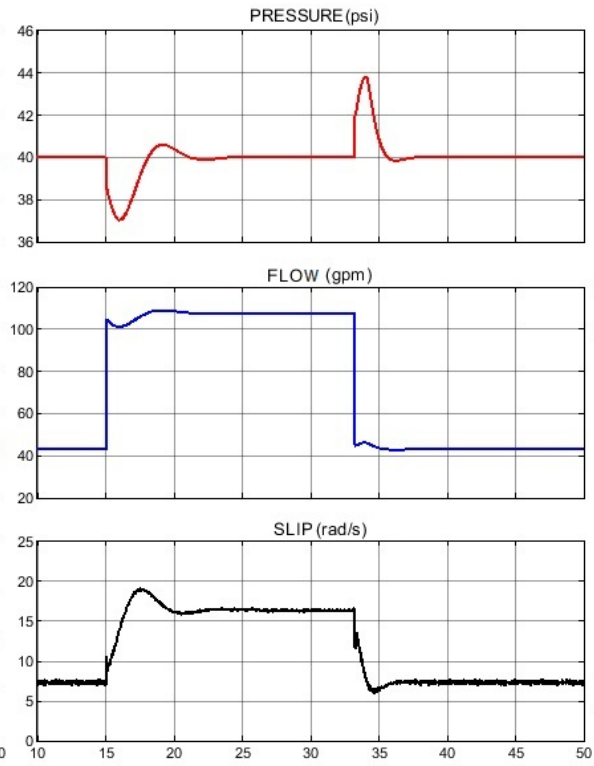

(b)
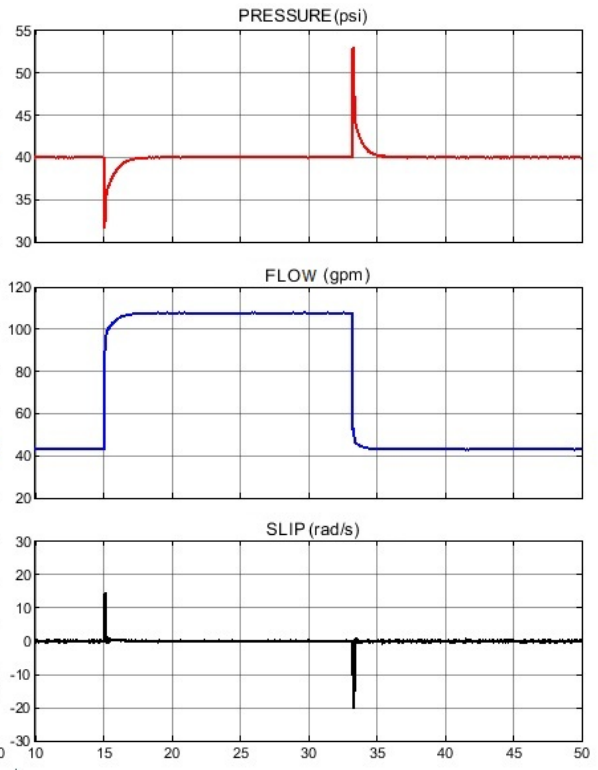

(c)

Figure 12. Comparison of the dynamic response under three different conditions: (a) with slip compensation and hydropneumatic tank; (b) without slip compensation; (c) without hydropneumatic tank.

In Figure 13, the results of test 2 are presented, where the dynamic response of several hydraulic and mechanical variables of interest is observed. Figure 13a shows the results 
of the first case study, and Figure $13 \mathrm{~b}$ the second case study. In both cases, very similar transient responses are observed for pressure and flow rate, and in a steady state, there were practically no differences. The dynamic response of the flow rate, total dynamic head, suction pressure, discharge pressure, angular velocity, and mechanical torque of each pump train is also appreciated. It is noticeable that in the pumps that operated at variable speeds, the angular speed and the mechanical torque increased and decreased with the flow demand. This action is what produces power savings.
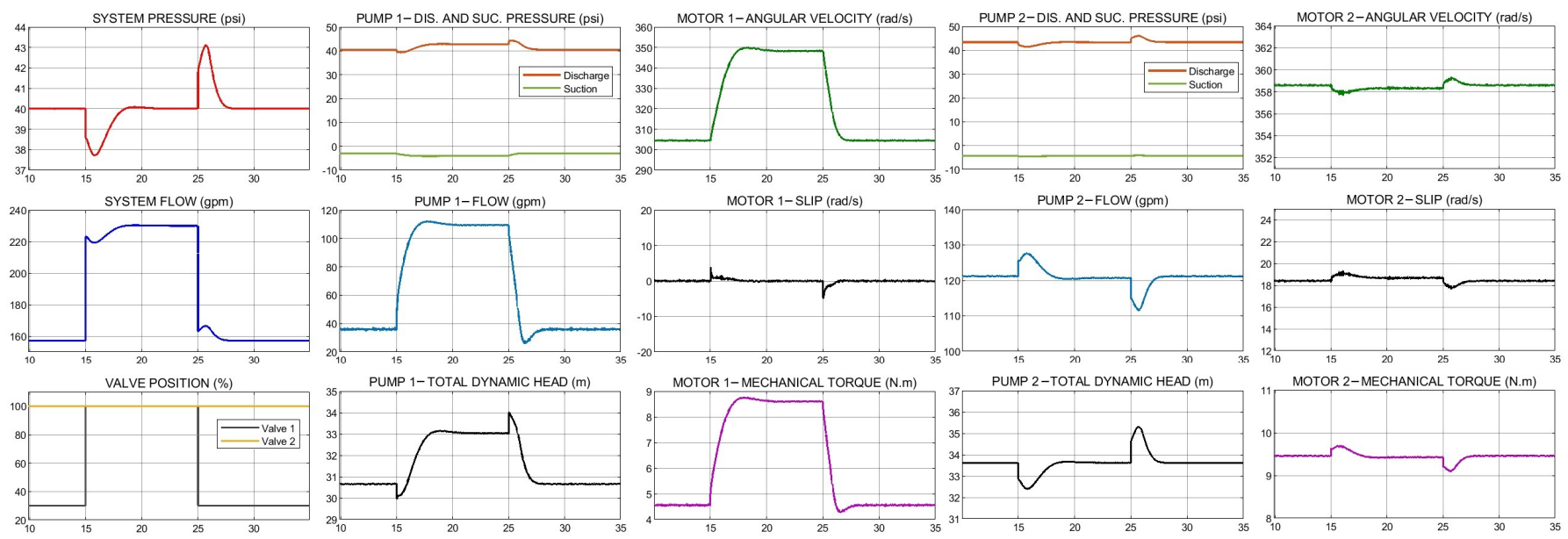

(a)
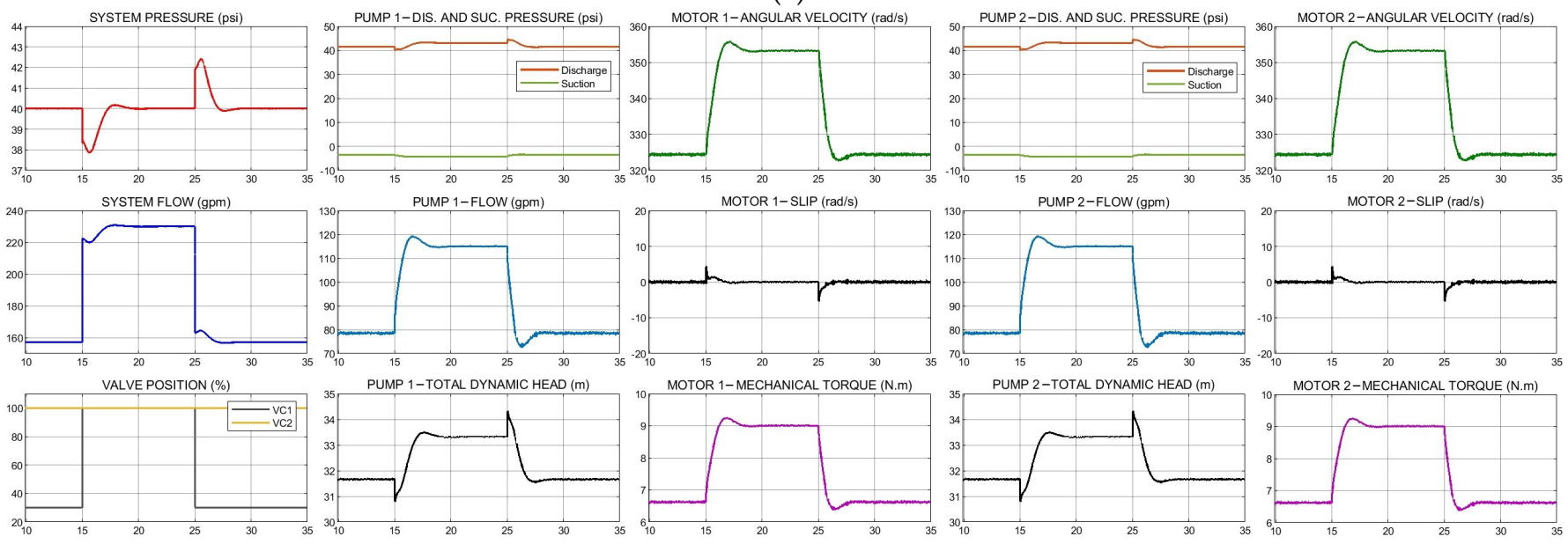

(b)

Figure 13. Dynamic response of the different hydraulic and mechanical variables of interest for a set point of 40 psi: (a) case study 1: a single pump at variable speed; (b) case study 2: both pumps at variable speed.

\subsection{Starting Current and Harmonic Distortion}

Figure 14 shows the waveforms of the currents and voltages during the induction motor starting process. Figure 14a corresponds to the direct start that occurred in the base case, through a direct connection to the electrical grid, a process that lasted approximately $200 \mathrm{~ms}$ (12 cycles). It is observed that the starting current was approximately 8.5 times the steady state current. On the other hand, Figure $14 \mathrm{~b}$ shows the starting process through the acceleration ramp of $3600 \mathrm{rpm} / \mathrm{s}$ provided by the variable speed. In this second case, it is observed that the starting current did not exceed three times the current in steady state (Figure 14b), therefore this transient current was reduced by $64.7 \%$ compared with the base case (Figure 14a). The frequency inverter smooths the starting and stopping (Figure 14b) which prevents some unwanted electrical, mechanical, and hydraulic effects produced in 
sudden starts and stops, such as water hammer and pressure peaks [43], vibrations in the pipes [44], voltage drops in the motor and the electrical grid [45], or mechanical stress that reduces the useful life of the motor [46].

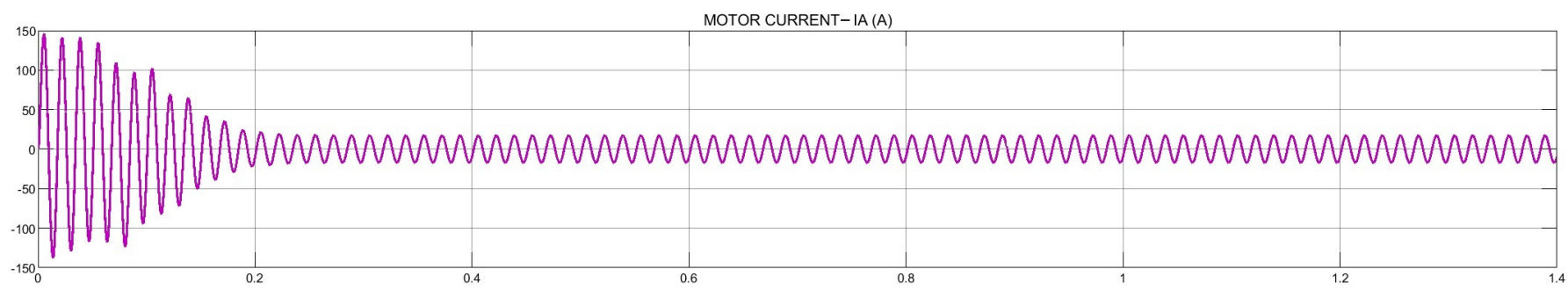

(a)

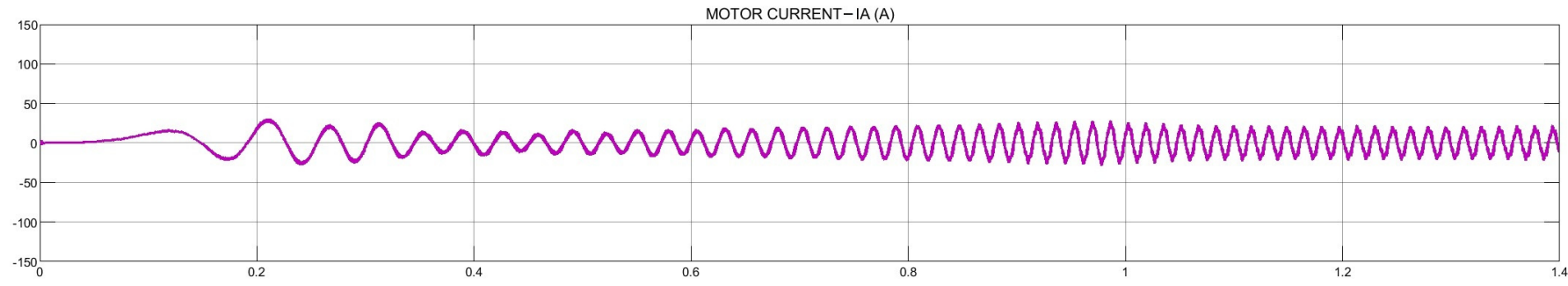

(b)

Figure 14. Currents and voltages during starting: (a) starting by direct connection to the grid; (b) starting by variable speed drive with $3600 \mathrm{rpm} / \mathrm{s}$ ramp.

When a pump operates at variable speed, the waveforms of the voltages and currents at the input and output of the drive are as shown in Figure 15a. The line voltage and current waveforms, for cases one and two, are presented in Figure 15b,c, respectively. For these simulations, a short-circuit power of the source of $450 \mathrm{kVA}$ and a ratio $\mathrm{X} / \mathrm{R}=10$ were considered. Distortions in current and voltage waveform are observed, which can be evaluated with a THD indicator.
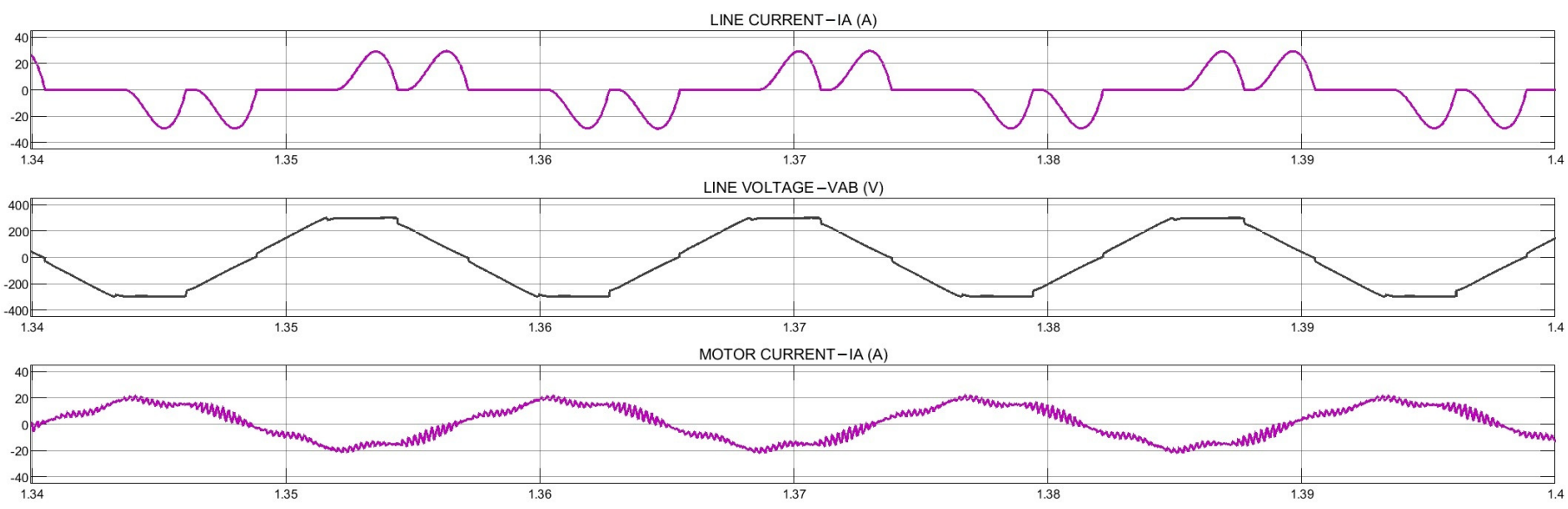

MOTOR CURRENT-VAB (V)

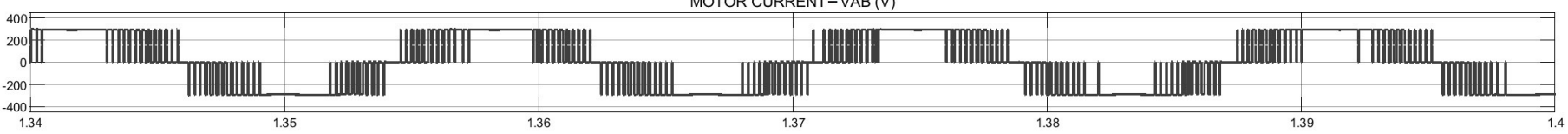

(a)

Figure 15. Cont. 

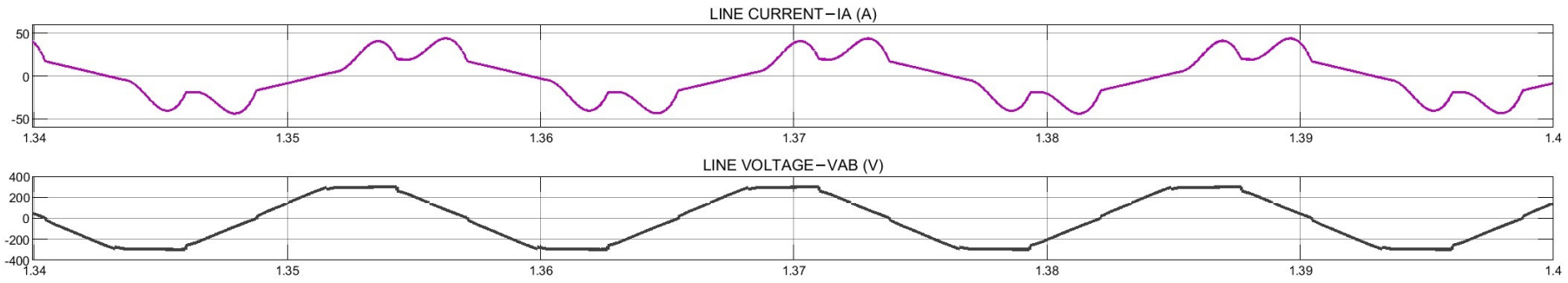

(b)
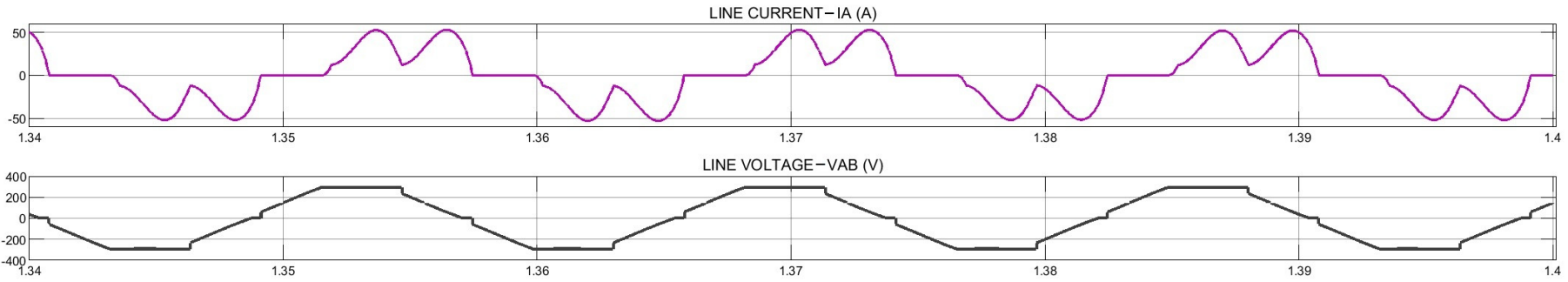

(c)

Figure 15. Steady-state currents and voltages: (a) Motor with variable speed drive; (b) case 1: one pump with a variable speed drive and the other with a direct connection to the grid; (c) case 2: both pumps with variable speed drive. The three scenarios at nominal speeds. The short circuit power of the source is $450 \mathrm{kVA}$, and the $\mathrm{X} / \mathrm{R}$ ratio is 10 .

Table 1 presents a summary of the total harmonic distortion (THD), an indicator that can be obtained using the Fast Fourier Transform (FFT), a tool that is part of Simulink's specialized "powergui" block.

Table 1. Total Harmonic Distortion (THD).

\begin{tabular}{ccccccc}
\hline \multirow{2}{*}{$\begin{array}{c}\text { Study } \\
\text { Case }\end{array}$} & \multirow{2}{*}{$\begin{array}{c}\text { Pumps } \\
\text { Running }\end{array}$} & \multirow{2}{*}{ Waveform } & \multicolumn{2}{c}{ Current } & \multicolumn{2}{c}{ Voltage } \\
\cline { 4 - 7 } & & Line & Motor & Line & Motor \\
\hline 1,2 & 1 & Figure 15a & 79.00 & 35.17 & 4.93 & 57.5 \\
1 & 2 & Figure 15b & 33.87 & - & 4.30 & - \\
2 & 2 & Figure 15c & 47.47 & - & 7.08 & - \\
\hline Valo
\end{tabular}

Values are in \%.

The noncontrolled rectifier bridge was responsible for the harmonic distortion on the line side, and the inverter IGBT bridge produced the motor side harmonic distortion. Harmonic pollution generates various unwanted effects on the electrical grid and the loads connected to it [47-49] and also damages the induction motor [50,51]. However, the switching of power semiconductors also produces the reflected wave phenomenon, although this was not observed in the simulation. The reflected wave is amplified if the distance between the frequency inverter and the motor increases, generating overvoltages harmful to the conductors and the induction motor and also damaging overcurrents for the frequency inverter $[52,53]$. The harmonic distortion and reflected wave can be mitigated by implementing filters $[49,53]$.

\subsection{Power Saving}

Table 2 shows the mechanical power required for the base case and the two study cases and also shows the percentage of mechanical power savings of the two study cases with respect to the base case. Eight operating scenarios defined by the opening percentage of consumption valves one and two were evaluated. With the torque and angular velocity data, the mechanical power was calculated using Equation (8). 
Table 2. Power consumption and savings for various operating scenarios.

\begin{tabular}{|c|c|c|c|c|c|c|c|}
\hline \multicolumn{3}{|c|}{ Scenarios } & \multicolumn{3}{|c|}{ Total Mechanical Power } & \multicolumn{2}{|c|}{$\begin{array}{c}\text { Savings Compared to the } \\
\text { Base Case }\end{array}$} \\
\hline $\begin{array}{l}\text { Valve } 1 \\
\% \%\end{array}$ & $\begin{array}{c}\text { Valve } 2 \\
\%\end{array}$ & Pumps Running & $\begin{array}{c}\text { Base Case } \\
\text { kW }\end{array}$ & $\begin{array}{c}\text { Case } 1 \\
\text { kW }\end{array}$ & $\begin{array}{c}\text { Case } 2 \\
\mathrm{~kW}\end{array}$ & $\begin{array}{c}\text { Case } 1 \\
\%\end{array}$ & $\begin{array}{c}\text { Case } 2 \\
\%\end{array}$ \\
\hline 100 & 100 & 2 & 6.75 & 6.55 & 6.70 & 3.07 & 0.83 \\
\hline 75 & 100 & 2 & 6.57 & 5.76 & 5.83 & 12.32 & 11.28 \\
\hline 50 & 100 & 2 & 6.33 & 5.29 & 5.06 & 16.40 & 20.07 \\
\hline 25 & 100 & 2 & 6.04 & 4.84 & 4.33 & 19.95 & 28.29 \\
\hline 0 & 100 & 1 & 3.47 & 3.72 & 3.72 & 7.43 & 7.43 \\
\hline 0 & 75 & 1 & 3.23 & 2.72 & 2.72 & 15.77 & 15.77 \\
\hline 0 & 50 & 1 & 2.88 & 1.92 & 1.92 & 33.41 & 33.41 \\
\hline 0 & 25 & 1 & 2.37 & 1.25 & 1.25 & 47.23 & 47.23 \\
\hline
\end{tabular}

In high-demand scenarios (two pumps in parallel), the mechanical power was reduced to $19.95 \%$ for case one and $28.29 \%$ for case two. With decreasing demand, both cases operate with a single pump at variable speed, and mechanical power savings of up to $47.23 \%$ were obtained compared with the base case at a fixed speed. This analysis did not consider the losses of the motor or the frequency inverter, since under nominal conditions, electric motors are more efficient than pumps, and frequency inverters more efficient than motors; However, the efficiency of the motor can change with variations in load torque and speed [54-56]. The efficiency of the electrical system with a variable speed drive can be reduced by up to $8 \%$ with respect to the efficiency of the system with direct connection to the grid, but this reduction is not significant in relation to the energy savings achieved [56].

\subsection{Investment Costs}

CAPEX is higher in solutions with variable speed drive compared with traditional solutions at a fixed speed. However, the improvement in performance allows savings during the operation and maintenance of the system that increase profitability considering the entire life cycle.

\subsection{Evaluation of the Case Studies}

Table 3 presents, as a summary, the evaluation criteria of the cases studied.

Table 3. Evaluation summary of the cases studied.

\begin{tabular}{|c|c|c|c|}
\hline \multirow{2}{*}{ Evaluation Criteria } & \multicolumn{3}{|c|}{ Study Case } \\
\hline & $\begin{array}{l}\text { Base Case: Fixed Speed } \\
\text { Pumps }\end{array}$ & $\begin{array}{c}\text { Case 1: One Variable Speed } \\
\text { Pump }\end{array}$ & $\begin{array}{l}\text { Case 2: Both Pumps at } \\
\text { Variable Speed }\end{array}$ \\
\hline Pressure Control & At 40 psi \pm hysteresis & Constant at 40 psi & Constant at 40 psi \\
\hline $\begin{array}{l}\text { Hydropneumatic tank } \\
\text { capacity }\end{array}$ & 80 gallons & 10 gallons & 10 gallons \\
\hline $\begin{array}{l}\text { Starting Current } \\
\text { Harmonic Content }\end{array}$ & $\begin{array}{l}\text { Up to } 8.5 \text { times nominal } \\
\text { No harmonics }\end{array}$ & $\begin{array}{c}\text { Up to } 3 \text { times the nominal } \\
\text { > THD }\end{array}$ & $\begin{array}{c}\text { Up to } 3 \text { times the nominal } \\
\gg \text { THD }\end{array}$ \\
\hline Save Energy & There are no savings & $\begin{array}{c}\text { Up to } 47.23 \% \text { savings in low } \\
\text { flow rates } \\
\text { Up to } 19.95 \% \text { savings in high } \\
\text { flow rates }\end{array}$ & $\begin{array}{c}\text { Up to } 47.23 \% \text { savings in low } \\
\text { flow rates } \\
\text { Up to } 28.29 \% \text { savings in high } \\
\text { flow rates }\end{array}$ \\
\hline Investment Costs & Less & Intermediate & Higher \\
\hline
\end{tabular}

Table 3 shows that both studied cases develop a better performance compared with the base case in terms of process quality and energy efficiency. In addition, both cases affect the quality of the electrical energy because of the harmonic pollution they produce and require a higher CAPEX compared with the base case. 


\section{Conclusions}

In this research, two cases were studied to achieve a constant pressure system in a pumping station consisting of two centrifugal pumps in parallel, powered by electricity, and subjected to variable flow demand. The analysis was numerical in nature with modeling and simulation of systems carried out in MATLAB/Simulink R2019b. In the first case, one pump was operated at a fixed speed and the other at a variable speed, while in the second case, both pumps operated at a variable speed. These case studies were compared with each other and also compared with the base case where both pumps operated at a fixed speed. The results showed that with variable speed drives, it is possible to have a pressure regulating control system, achieving constant pressure in the face of variable flow demands, which is not achieved in the base case. In addition, variable speed drives smooth the current during acceleration and deceleration, leading to energy savings during startup and preventing unwanted electrical, mechanical, and hydraulic problems that are generated in sudden starts and stops (base case). Both study cases managed to reduce the required power by up to $47 \%$ compared with the base case. The second case obtained first place in energy efficiency by considering a variable speed drive in each pump. The harmonic distortion produced by frequency inverters was observed both on the line side and on the motor side. The harmonic distortion on the line side was higher in the second case, having two frequency inverters in parallel. This phenomenon can produce serious problems in the electrical grid, third-party equipment connected to the grid, and in induction motors, but it can be treated by implementing filters. The developed model is useful to study other control strategies that allow raising the degree of quality and efficiency of the pumping system, as well as harmonic filtering systems to improve the quality of energy.

Author Contributions: Conceptualization, R.J.A.-C. and J.A.P.-R.; methodology, C.D.A.-J. and C.G.R.B.; software, R.J.A.-C.; validation, C.G.R.-B. and J.D.B.-E.; formal analysis, R.J.A.-C., J.A.P.-R., Y.E.L.-A. and C.D.A.-J.; investigation, R.J.A.-C.; resources, J.D.B.-E.; data curation, C.G.R.-B.; writing-original draft preparation, C.D.A.-J. and R.J.A.-C.; writing-review and editing, J.A.P.-R.; visualization, J.D.B.-E.; supervision, Y.E.L.-A. All authors have read and agreed to the published version of the manuscript.

Funding: This research received no external funding.

Institutional Review Board Statement: Not applicable.

Informed Consent Statement: Not applicable.

Data Availability Statement: Not applicable.

Conflicts of Interest: The authors declare no conflict of interest.

\section{Abbreviations and Symbols}

$\begin{array}{ll}q_{\text {nom }} & \text { Nominal flow rate of the pump } \\ q & \text { Arbitrary flow rate } \\ \omega_{\text {nom }} & \text { Nominal angular velocity of the pump } \\ \omega & \text { Arbitrary angular velocity } \\ \rho_{\text {nom }} & \text { Density of the fluid at nominal values } \\ \rho & \text { Density of the fluid at arbitrary values } \\ p_{\text {nom }} & \text { Differential pressure at nominal flow rate } \\ p & \text { Differential pressure at arbitrary flow rate } \\ P_{\text {hyd_nom }} & \text { Hydraulic power at nominal conditions } \\ P_{\text {hyd }} & \text { Hydraulic power at arbitrary conditions } \\ P_{h y d 0} & \text { Theoretical hydraulic power } \\ p_{E} & \text { Euler pressure } \\ P_{f r} & \text { Power of friction losses } \\ T_{0} & \text { Constant torque on the impeller shaft } \\ k_{p} & \text { Torque-pressure relationship }\end{array}$




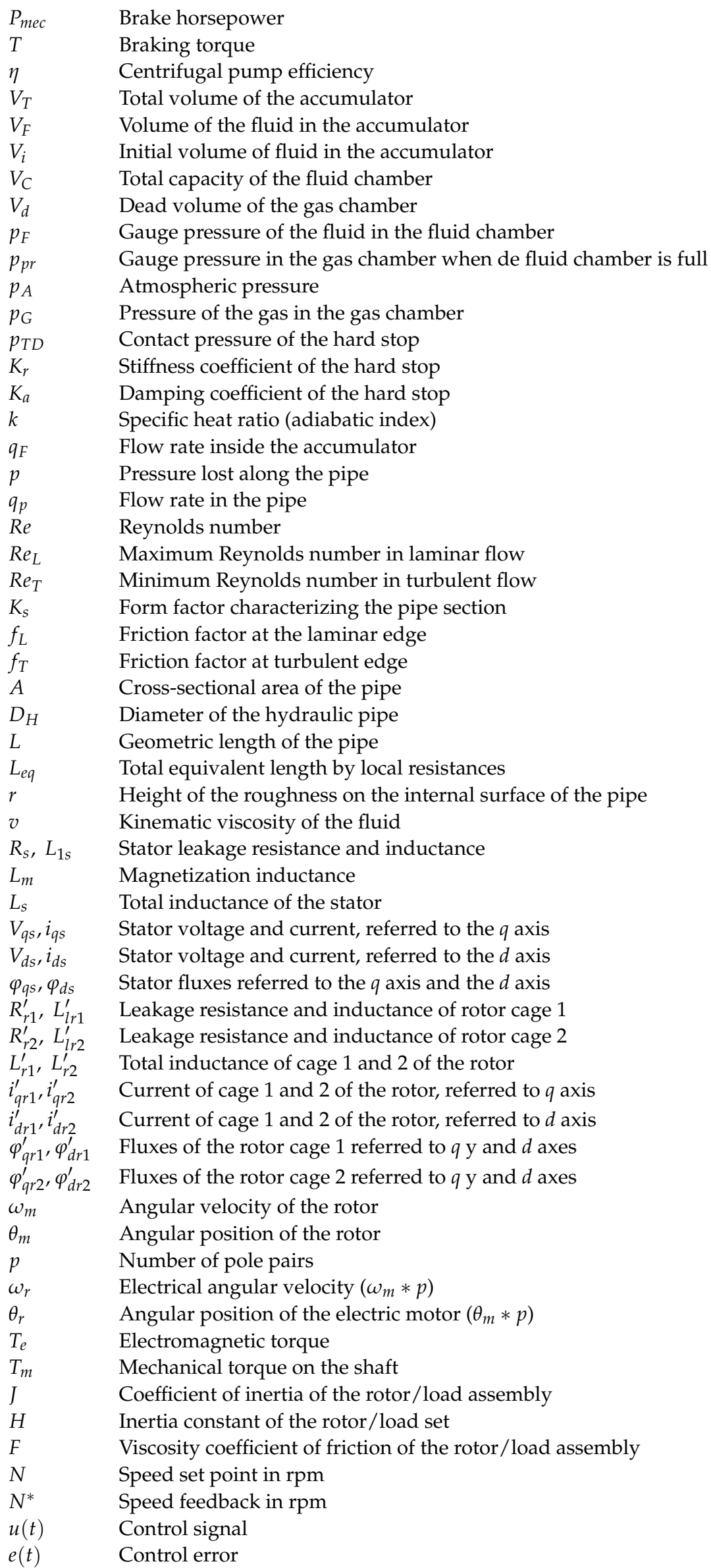




$\begin{array}{ll}K_{p} & \text { Proportional gain } \\ T_{i} & \text { Integral time } \\ T_{d} & \text { Derivative time } \\ \text { BEP } & \text { Best efficiency point } \\ \text { PI } & \text { Proportional and integral } \\ \text { PID } & \text { Proportional, integral and derivative } \\ \text { PLC } & \text { Programmable logic controller } \\ \text { POR } & \text { Preferred operating region } \\ \text { PWM } & \text { Pulse with modulation } \\ \text { SVM } & \text { Space vector modulation } \\ \text { THD } & \text { Total harmonic distortion } \\ \text { V/f } & \text { Voltage/frequency ratio } \\ \text { VSI } & \text { Voltage source inverter } \\ \text { VSD } & \text { Variable speed drive }\end{array}$

\section{References}

1. Werkhoven, M.V.; Werle, R.; Brunner, C.U. Policy Guidelines for Motor Driven Units. Part 2: Recommendations for Aligning Standards and Regulations for Pumps, Fans and Compressors; 4E Electric Motor Systems Annex: Zurich, Switzerland, 2018. Available online: https:/ / www.iea-4e.org/wp-content/uploads/publications/2018/05/PGMdu_Final_250418.pdf (accessed on 14 October 2021).

2. Rakibuzzaman, M.; Kim, K.; Kim, H.-H.; Suh, S.-H. Energy saving rates for a multistage centrifugal pump with variable speed drive. J. Power Technol. 2017, 97, 163-168.

3. Shankar, V.K.A.; Umashankar, S.; Paramasivam, S.; Norbert, H. Real time simulation of Variable Speed Parallel Pumping system. Energy Procedia 2017, 142, 2102-2108. [CrossRef]

4. Arun Shankar, V.K.; Umashankar, S.; Paramasivam, S.; Hanigovszki, N. A comprehensive review on energy efficiency enhancement initiatives in centrifugal pumping system. Appl. Energy 2016, 181, 495-513. [CrossRef]

5. Andrade-Cedeno, R. Gestión Energética de una Estación de Bombeo mediante el uso del Control Estadístico de Procesos. Estudio de Caso: Acueducto "La Esperanza"—Refinería del Pacífico. Rev. Politécnica 2018, 40, 7-18.

6. Arun Shankar, V.K.; Umashankar, S.; Padmanaban, S.; Bhaskar, M.S.; Almakhles, D. Investigation for Performances Comparison PI, Adaptive PI, Fuzzy Speed Control Induction Motor for Centrifugal Pumping Application. In Proceedings of the 2019 IEEE 13th International Conference on Compatibility, Power Electronics and Power Engineering (CPE-POWERENG), Sonderborg, Denmark, 23-25 April 2019; pp. 1-6. [CrossRef]

7. Boldea, I.; Moldovan, A.; Tutelea, L. Scalar V/f and I-f control of AC motor drives: An overview. In Proceedings of the 2015 Intl Aegean Conference on Electrical Machines \& Power Electronics (ACEMP), 2015 Intl Conference on Optimization of Electrical \& Electronic Equipment (OPTIM) \& 2015 Intl Symposium on Advanced Electromechanical Motion Systems (ELECTROMOTION), Side, Turkey, 2-4 September 2015; pp. 8-17.

8. Elan, S.; Aishwarya, A. Simulation \& Development of Inverter Fed Three Phase Induction Motor Using V/f Control Strategy. Int. J. Emerg. Technol. Adv. Eng. 2014, 4, 151-156.

9. Zhang, Z.; Liu, Y.; Bazzi, A.M. An improved high-performance open-loop V/f control method for induction machines. In Proceedings of the 2017 IEEE Applied Power Electronics Conference and Exposition (APEC), Tampa, FL, USA, 26-30 March 2017; pp. 615-619. [CrossRef]

10. Chitra, A.; Sultana, W.R.; Vanishree, J.; Sreejith, S.; Jose, S.; Pulickan, A.J. Performance Comparison of Multilevel Inverter Topologies for Closed Loop v/f Controlled Induction Motor Drive. Energy Procedia 2017, 117, 958-965. [CrossRef]

11. Nasser, A.; Szemes, P.T. Speed Control of Three Phase Induction Motor Using Scalar Method and PID Controller. Recent Innov. Mechatron. (RIiM) 2018, 5, 1-5. [CrossRef]

12. Behera, P.K.; Behera, M.K.; Sahoo, A.K. Speed Control of Induction Motor using Scalar Control Technique. IJCA Proc. Int. Conf. Emerg. Trends Comput. Commun. ETCC 2014, 1, 37-39.

13. Hartono, H.; Sudjoko, R.I.; Iswahyudi, P. Speed Control of Three Phase Induction Motor Using Universal Bridge and PID Controller. J. Phys. Conf. Ser. 2019, 1381, 1-8. [CrossRef]

14. Moreano Peña, J.; Vásquez Díaz, E. Implementation of V/f scalar control for speed regulation of a three-phase induction motor. In Proceedings of the 2016 IEEE ANDESCON, Arequipa, Peru, 19-21 October 2016; pp. 1-4. [CrossRef]

15. Andrade-Cedeno, R.; Perez-Rodriguez, J.A. Análisis del control V/f con SVM en un accionamiento de velocidad variable Dominios De La Cienc. 2021, 7, 38-62.

16. Lysenko, O.A.; Simakov, A.V. The Pump Hydraulic Load Effect Determination on the Parameters of an Frequency-Controlled Asynchronous Electric Drive. In Proceedings of the XIII International Scientific and Technical Conference "Dynamics of Systems, Mechanisms and Machines" (Dynamics), Omsk, Russia, 5-7 November 2019; pp. 1-6. [CrossRef]

17. Abdelwanis, M.I.; Selim, F. A sensorless six-phase induction motor driving a centrifugal pump system. In Proceedings of the 2017 Nineteenth International Middle East Power Systems Conference (MEPCON), Cairo, Egypt, 19-21 December 2017; pp. 242-247. [CrossRef] 
18. Gevorkov, L.; Vodovozov, V.; Raud, Z. Simulation study of the pressure control system for a centrifugal pump. In Proceedings of the 2016 57th International Scientific Conference on Power and Electrical Engineering of Riga Technical University (RTUCON), Riga, Latvia, 13-14 October 2016; pp. 1-5. [CrossRef]

19. Arun Shankar, V.K.; Umashankar, S.; Paramasivam, S.; Hanigovszki, N. An Energy Efficient Control Algorithm for Parallel Pumping Industrial Motor Drives System. In Proceedings of the 2018 IEEE International Conference on Power Electronics, Drives and Energy Systems (PEDES), Chennai, India, 23-25 April 2019; pp. 1-6. [CrossRef]

20. Oshurbekov, S.; Kazakbaev, V.; Prakht, V.; Dmitrievskii, V.; Gevorkov, L. Energy Consumption Comparison of a Single VariableSpeed Pump and a System of Two Pumps: Variable-Speed and Fixed-Speed. Appl. Sci. 2020, 10, 8820. [CrossRef]

21. Viholainen, J. Energy-efficient control strategies for variable speed driven parallel pumping systems based on pump operation point monitoring with frequency converters. Ph.D. Thesis, Lappeenranta University of Technology, Lappeenranta, Finlandia, 2014.

22. Andrade-Cedeño, R. Módulo didáctico para controlar nivel y caudal de agua, mediante sistema SCADA, PLC y algoritmo PID. RIEMAT 2019, 4, 50-62. [CrossRef]

23. Sarbu, I.; Valea, E.S. Energy Savings Potential for Pumping Water in District Heating Stations. Sustainability 2015, 7, 5705-5719. [CrossRef]

24. Al-Ani, D.S. Energy Optimization Strategy for System-Operational Problems. Ph.D. Thesis, McMaster University, Hamilton, ON, Canada, 2012.

25. ANSI; Hydraulic Institute. Rotodynamic (Centrifugal and Vertical) Pumps-Guideline for Allowable Operating Region (ANSI/HI 9.6.3-2017); Hydraulic Institute: Parsippany, NJ, USA, 2017.

26. Ahmed, A.; Moharam, B.; Rashad, E. Power Saving of Multi Pump-Motor Systems Using Variable Speed Drives. In Proceedings of the 2018 Twentieth International Middle East Power Systems Conference (MEPCON), Cairo, Egypt, 18-20 December 2018; pp. 839-844. [CrossRef]

27. Bharti, R.; Kumar, M.; Prasad, B.M. V/F Control of Three Phase Induction Motor. In Proceedings of the 2019 International Conference on Vision Towards Emerging Trends in Communication and Networking (ViTECoN), Vellore, India, 30-31 March 2019; pp. 1-4. [CrossRef]

28. Anjum, F.; Sharma, N. Speed Control of Induction Motor using Hybrid PID Fuzzy Controller. Int. Res. J. Eng. Technol. (IRJET) 2018, 5, 576-580.

29. Arnanz, R.; García, F.J.; Miguel, L.J. Métodos de control de motores de inducción: Síntesis de la situación actual. Rev. Iberoam. De Automática E Inf. Ind. RIAI 2016, 13, 381-392. [CrossRef]

30. Pati, S.; Patnaik, M.; Panda, A. Comparative performance analysis of fuzzy PI, PD and PID controllers used in a scalar controlled induction motor drive. In Proceedings of the 2014 International Conference on Circuits, Power and Computing Technologies [ICCPCT-2014], Nagercoil, India, 20-21 March 2014; pp. 910-915. [CrossRef]

31. Bonavita, N. How process automation can increase energy efficiency. In Hydrocarbon Processing; Gulf Energy Information: Genoa, Italy, 2013; pp. 71-75. Available online: https://library.e.abb.com/public/953141f99f2f77f985257b810060bb17/Hydrocarbon\%20 Processing\%20June\%202013\%20Energy\%20Efficiency.pdf (accessed on 3 December 2021).

32. Likins, M. PID tuning improves process efficiency. In Control Engineering; CFE Media and Technology: Downers Grove, IL, USA, 2013. Available online: https://www.controleng.com/articles/pid-tuning-improves-process-efficiency/ (accessed on 10 December 2021).

33. Gomes, F.J.; Queiroz, F.P.; Lopes, I.F.; Coelho, A.A.R. Energy Savings in Industrial Processes: A Case Study of Strategies and Tuning Procedures for PI and PID Controllers. IFAC Proc. Vol. 2012, 45, 607-612. [CrossRef]

34. MathWorks Help Center. Centrifugal Pump with Choice of Parameterization Options. Available online: https://la.mathworks. com/help/physmod/hydro/ref/centrifugalpump.html (accessed on 12 January 2022).

35. MathWorks Help Center. Hydraulic Accumulator with Gas as Compressible Medium. Available online: https:/ /la.mathworks. $\mathrm{com} /$ help/physmod/hydro/ref/gaschargedaccumulator.html (accessed on 12 January 2022).

36. MathWorks Help Center. Hydraulic Resistive Tube. Available online: https://la.mathworks.com/help/physmod/simscape/ref/ hydraulicresistivetube.html (accessed on 12 January 2022).

37. MathWorks Help Center. Transformadas de Clarke y Park. Available online: https://la.mathworks.com/solutions/powerelectronics-control/clarke-and-park-transforms.html (accessed on 12 January 2022).

38. MathWorks Help Center. Universal Bridge. Available online: https://la.mathworks.com/help/physmod/sps/powersys/ref/ universalbridge.html (accessed on 12 January 2022).

39. MathWorks Help Center. Space Vector PWM VSI Induction Motor Drive. Available online: https://la.mathworks.com/help/ physmod/sps/powersys/ref/spacevectorpwmvsiinductionmotordrive.html (accessed on 12 January 2022).

40. Ogata, K. Ingeniería de Control Moderna; Pearson Educación S.A.: Madrid, Spain, 2010.

41. Latchooomun, L.; Sockalingum, T.; Poullé, K.V.; King, R.T.F.A.; Busawon, K.K.; Barbot, J.P. Design of a Water Pressure Boosting System for Pressure-Driven Demand in a Distribution Network. In Proceedings of the 2018 5th International Symposium on Environment-Friendly Energies and Applications (EFEA), Rome, Italy, 24-26 September 2018; pp. 1-6. [CrossRef]

42. Khayatzadeh, F.; Ghafouri, J. Dynamical modeling of frequency controlled variable speed parallel multistage centrifugal pumps. Arch. Mech. Eng. 2015, 62, 347-361. [CrossRef]

43. Greenwood, S. Soft starter benefits in pump control. World Pumps 2015, 2015, 24-27. [CrossRef] 
44. Lale, D.; Oršulić, M.; Palunko, I. Modelling and soft-start control of measurement and transport line. In Proceedings of the 2020 International Conference on Smart Systems and Technologies (SST), Osijek, Croatia, 14-16 October 2020; pp. 59-64. [CrossRef]

45. Matanov, N. Study of the impact of induction motors starting on the supply voltage. In Proceedings of the 2019 16th Conference on Electrical Machines, Drives and Power Systems (ELMA), Varna, Bulgaria, 6-8 June 2019; pp. 1-5. [CrossRef]

46. Habyarimana, M.; Dorrell, D.G. Methods to reduce the starting current of an induction motor. In Proceedings of the 2017 IEEE International Conference on Power, Control, Signals and Instrumentation Engineering (ICPC-SI), Chennai, India, 21-22 September 2017; pp. 34-38. [CrossRef]

47. Zare, F.; Soltani, H.; Kumar, D.; Davari, P.; Delpino, H.A.M.; Blaabjerg, F. Harmonic Emissions of Three-Phase Diode Rectifiers in Distribution Networks. IEEE Access 2017, 5, 2819-2833. [CrossRef]

48. Srividhya, J.P.; Sivakumar, D.; Shanmathi, T. A Review on causes, effects, and detection techniques of harmonics in the power system. In Proceedings of the 2016 International Conference on Computation of Power, Energy Information and Commuincation (ICCPEIC), Melmaruvathur, India, 20-21 April 2016; pp. 680-686. [CrossRef]

49. Kalair, A.; Abas, N.; Kalair, A.R.; Saleem, Z.; Khan, N. Review of harmonic analysis, modeling and mitigation techniques. Renew. Sustain. Energy Rev. 2017, 78, 1152-1187. [CrossRef]

50. Beleiu, H.G.; Maier, V.; Pavel, S.G.; Birou, I.; Pică, C.S.; Dărab, P.C. Harmonics Consequences on Drive Systems with Induction Motor. Appl. Sci. 2020, 10, 1528. [CrossRef]

51. Zhang, D.; An, R.; Wu, T. Effect of voltage unbalance and distortion on the loss characteristics of three-phase cage induction motor. IET Electr. Power Appl. 2018, 12, 264-270. [CrossRef]

52. Narayanasamy, B.; Sathyanarayanan, A.S.; Deshpande, A.; Luo, F. Impact of cable and motor loads on wide bandgap device switching and reflected wave phenomenon in motor drives. In Proceedings of the 2017 IEEE Applied Power Electronics Conference and Exposition (APEC), Tampa, FL, USA, 26-30 March 2017; pp. 931-937. [CrossRef]

53. Narayanasamy, B.; Sathyanarayanan, A.S.; Luo, F.; Chen, C. Reflected Wave Phenomenon in SiC Motor Drives: Consequences, Boundaries, and Mitigation. IEEE Trans. Power Electron. 2020, 35, 10629-10642. [CrossRef]

54. Lozanov, Y.; Tzvetkova, S.; Petleshkov, A. Study of the effectiveness of a variable frequency drive of an induction motor. In Proceedings of the 2019 11th Electrical Engineering Faculty Conference (BulEF), Varna, Bulgaria, 11-14 September 2019; pp. 1-6. [CrossRef]

55. Agamloh, E.; Cavagnino, A.; Vaschetto, S. Induction Machine Efficiency at Variable Frequencies. In Proceedings of the 2019 IEEE Energy Conversion Congress and Exposition (ECCE), Baltimore, MD, USA, 29 September-3 October 2019; pp. 1655-1662. [CrossRef]

56. Burt, C.; Piao, X.; Gaudi, F.; Busch, B.; Taufik, N.F. Electric Motor Efficiency under Variable Frequencies and Loads. J. Irrig. Drain. Eng.-ASCE 2008, 134, 129-136. [CrossRef] 